OPEN ACCESS

Edited by:

Carla Pinheiro,

New University of Lisbon, Portugal

Reviewed by:

Claudio Lovisolo,

University of Turin, Italy

Alicia Pou,

Institute of Vine and Wine Sciences

(ICWV), Spain

*Correspondence:

Sahap Kaan Kurtural

skkurtura/@ucdavis.edu

tORCID:

Runze Yu

orcid.org/0000-0002-2816-2015

Luca Brillante

orcid.org/0000-0002-5747-6312

Johann Martínez-Lüscher orcid.org/0000-0002-3077-1346

Sahap Kaan Kurtura orcid.org/0000-0001-9578-831X

$¥$ Present address: Luca Brillante,

Department of Viticulture and Enology, California State University, Fresno,

$C A$, United States

Johann Martínez-Lüscher, Semios Technologies Inc., Fresno,

CA, United States

Specialty section:

This article was submitted to

Plant Abiotic Stress,

a section of the journal

Frontiers in Plant Science

Received: 20 March 2020

Accepted: 18 May 2020

Published: 23 June 2020

Citation:

Yu R, Brillante L,

Martínez-Lüscher $J$ and Kurtural SK (2020) Spatial Variability of Soil and Plant Water Status and Their Cascading Effects on Grapevine Physiology Are Linked to Berry and Wine Chemistry.

Front. Plant Sci. 11:790. doi: 10.3389/fp/s.2020.00790

\section{Spatial Variability of Soil and Plant Water Status and Their Cascading Effects on Grapevine Physiology Are Linked to Berry and Wine Chemistry}

\author{
Runze Yut, Luca Brillante ${ }^{\dagger \neq}$, Johann Martínez-Lüschert‡ and Sahap Kaan Kurtural*t \\ Department of Viticulture and Enology, University of California, Davis, Davis, CA, United States
}

The relationships between differences in plant water status, induced by spatial variability in soil texture, and the changes in berry and wine composition were investigated in an irrigated Cabernet Sauvignon (Vitis vinefera L.) vineyard for 2 years. A stratified and an equidistant grid were overlaid on the vineyard to characterize the soil texture by proximal sensing, soil sampling, and grapevine physiological and berry chemical development. Based on the mid-day stem water potential $\left(\Psi_{\text {stem }}\right)$ integrals, the vineyard was divided into two functional homogenous zones: Zone 1 with higher water stress and Zone 2 with lower water. Zone 1 consistently had lower $\Psi_{\text {stem }}$, net carbon assimilation, and stomatal conductance in both years. Berry weight and titratable acidity were lower in Zone 1 at harvest. Zone 2 reached 26 and $24^{\circ} \mathrm{Bx}$ total soluble solids (TSS) at harvest in Years 1 and 2, respectively, with higher TSS values of 30 and $27^{\circ} \mathrm{Bx}$ in Zone 1. Ravaz index did not vary spatially. Fruits were harvested differentially in both years and vinified separately from the two zones. In Year 1, all berry skin anthocyanin derivatives, tri-, di- hydroxylated, and total anthocyanins concentrations were higher in Zone 2. However, in Year 2, only malvidin, tri-hydroxylated, and total anthocyanins were higher in Zone 1. There were no differences in wine flavonoids in Year 2 when harvest commenced earlier. In both years,

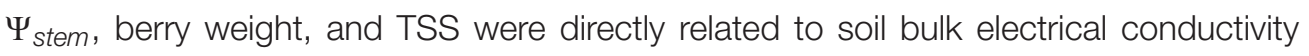
(EC). Our results indicated vineyard variability stemmed from soil texture that affected long-term plant water status which does not affect spatial variability of Ravaz Index. In conclusion, our work provides fundamental knowledge about the applicability of soil bulk EC sensing in the vineyards, and its potential directional utilization by connecting proximal soil sensing to spatial distribution of whole-plant physiological performance together with berry and wine chemistry.

Keywords: viticulture, plant water status, soil electrical conductivity, spatial variability, flavonoids, wine

\section{INTRODUCTION}

There is natural spatial variability present in vineyards due to the variations in soil characteristics and topography (Brillante et al., 2016a). Soil characteristics are too complex to be thoroughly surveyed effortlessly. With traditional destructive methods, it is difficult to obtain enough comprehensive information from the soil pits at the field scale. These soil characteristics may 

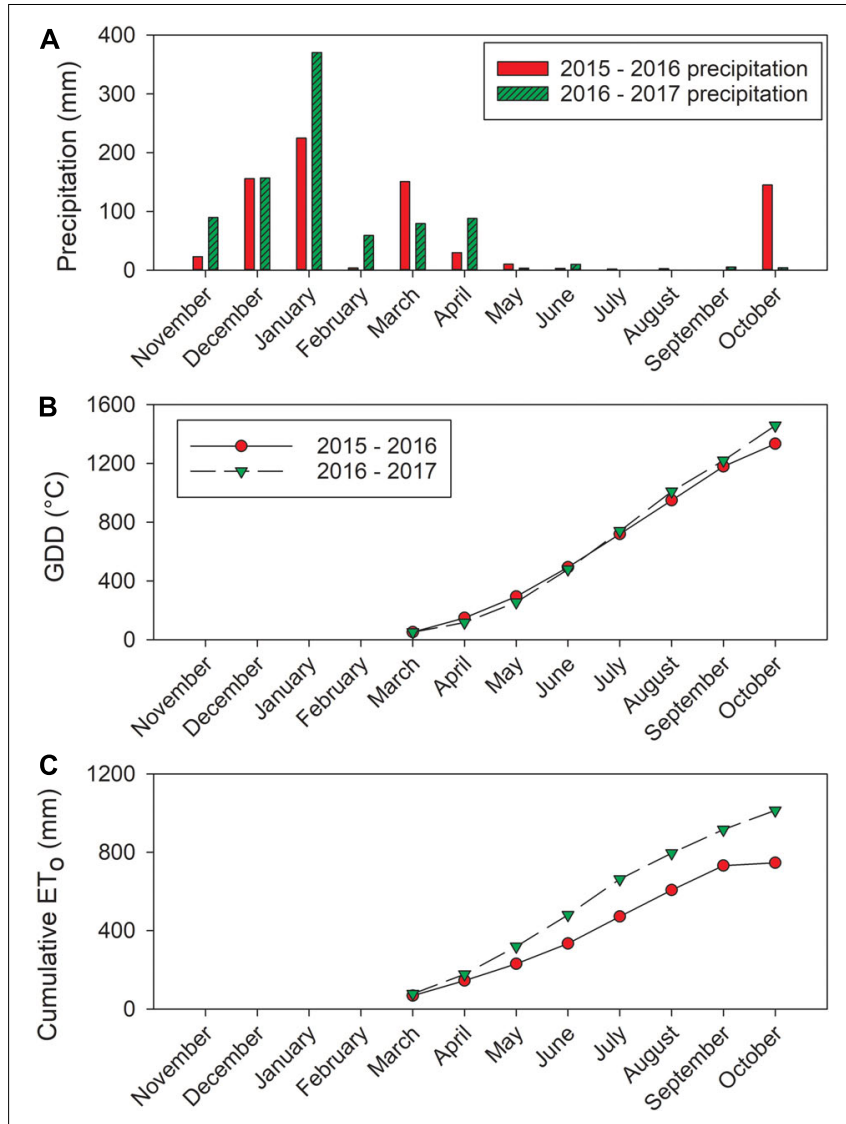

FIGURE 1 | Weather data acquired from California Irrigation Management Information System (CIMIS) station (\#86, Santa Rosa, CA). (A) Precipitation, (B) calculated GDD, and (C) cumulative $\mathrm{ET}_{0}$.

directly affect the water availability for grapevines, which eventually determine the physiological performance of the plants (Brillante et al., 2015, 2016a). However, there is no variable management practices currently available to accommodate the natural spatial variability. Thus, the spatial variability derived from vineyard soils will inevitably be expressed in the whole plant physiology at the cost of homogeneity of vineyard productivity and quality. We previously reported the spatial variation of midday stem water potential affecting grapevine carbon assimilation and stomatal conductance of grapevine (Brillante et al., 2017; $\mathrm{Yu}$ and Kurtural, 2020). The resultant variations in wholeplant physiology were associated to flavonoid composition and concentration at the farm gate. However, there is a lack of information about the effects on the chemical composition in the final wine, which would ultimately determine wine quality as perceived by consumers.

Georeferenced proximal sensing tools can capture the spatial and temporal variability in vineyards, making it possible to supervise and manage variations at the field scale (Bramley et al., 2011c; Matese et al., 2015). Previous studies showed that soil bulk electrical conductivity (EC) may be used to evaluate many soil attributes, including soil moisture content, salinity, and texture (Brillante et al., 2014; Su et al., 2014). Soil electromagnetic induction (EMI) sensing has been used in precision agriculture to acquire soil bulk EC at the field scale due to its non-invasive and prompt attributes (Bramley et al., 2011a; Rodríguez-Pérez et al., 2011). Although research had been conducted on the relationships between soil electrical properties with plant water status, they were mostly point measurements and the results were rarely interpolated to whole fields. There were only a few studies that investigated the EMI sensing and soil-plant water relationships over a vineyard (Bonfante et al., 2015). Previous research suggested that the connection between soil water content and soil bulk EC could have relied on specific soil profiles, and needed to include soil physical and chemical properties to complete this connection (Brillante et al., 2014, 2016a). Nevertheless, there is evidence that soil bulk EC may still be useful not only to identify the variability in soil, but also in the plant response affected by vineyard soils such as yield, plant physiology, and grape berry chemistry (Bramley et al., 2011a; Tagarakis et al., 2013).

Plant available water is a determinant factor on grapevine physiology, together with nitrogen availability in semi-arid regions (Smart and Coombe, 1983). Wine grapes are usually grown under a moderate degree of water deficits as yields were optimized at $80 \%$ of crop evapotranspiration demand with sustained deficit irrigation (Williams, 2012). Water deficits would limit leaf stomatal conductance and carbon assimilation rate that sustain grapevines' vegetative and reproductive growth and development (Escalona et al., 2015). When grapevines are under water deficits, carbohydrates repartitioned into the smaller berries would enhance berry soluble solids content (Escalona et al., 2015). Sucrose and fructose, which are the major components of total soluble solids (TSS) in grape berry, can act as a signaling factor to stimulate anthocyanin accumulation (Dai et al., 2014). The effects on grapevine physiology and berry composition also depend on the phenological stages they occur and how severe and prolonged the water deficits are (Intrigliolo and Castel, 2010).

Flavonoids are the most critical compounds dictating many qualitative traits in both grape berries and wine (Lorrain et al., 2013). The variations in environmental factors could alter the concentration and biosynthesis of flavonoids and can be extrapolated spatially within the same vineyard, including water deficits (Castellarin et al., 2007b), solar radiation (MartínezLüscher et al., 2019), and air temperature (Spayd et al., 2002). Among flavonoid compounds, anthocyanins are responsible for the color of berry skin as well as wine (Intrigliolo and Castel, 2010). Moderate water deficits during growing season can increase anthocyanin concentration in berry skin and wine (Cortell et al., 2007). However, water deficits can impair plant temperature regulation through evaporative cooling (Tombesi et al., 2015). They may also inhibit berry growth by limiting berry size and altering berry skin weight (Castellarin et al., 2007a; Santesteban et al., 2011). Thus, in some cases it may be uncertain if water deficit promotes anthocyanins biosynthesis or reduces berry growth, or contributes to anthocyanin degradation (Petrussa et al., 2013). Applying water deficit on grapevines can contribute to greater proportion in tri-hydroxylated over dihydroxylated anthocyanins due to the up-regulation of $\mathrm{F}^{\prime} 5^{\prime} \mathrm{H}$ 

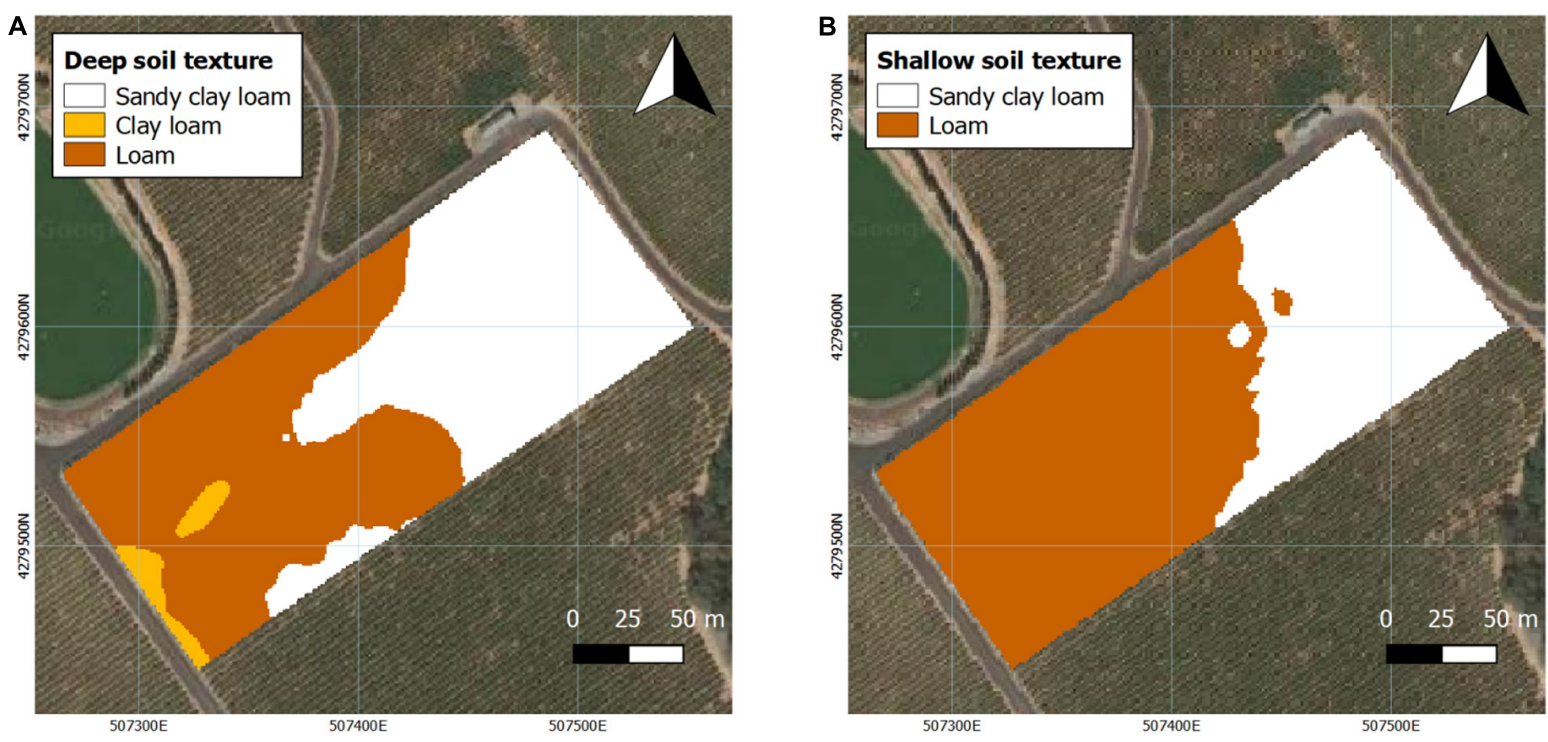

FIGURE 2 | Interpolated projection of soil texture at two depths assessed in 2016 and 2017. (A) Deep soil (0.75-1.5 m), (B) shallow soil (0-0.75 m). Coordinate system: WGS 1984 UTM Zone 10N.
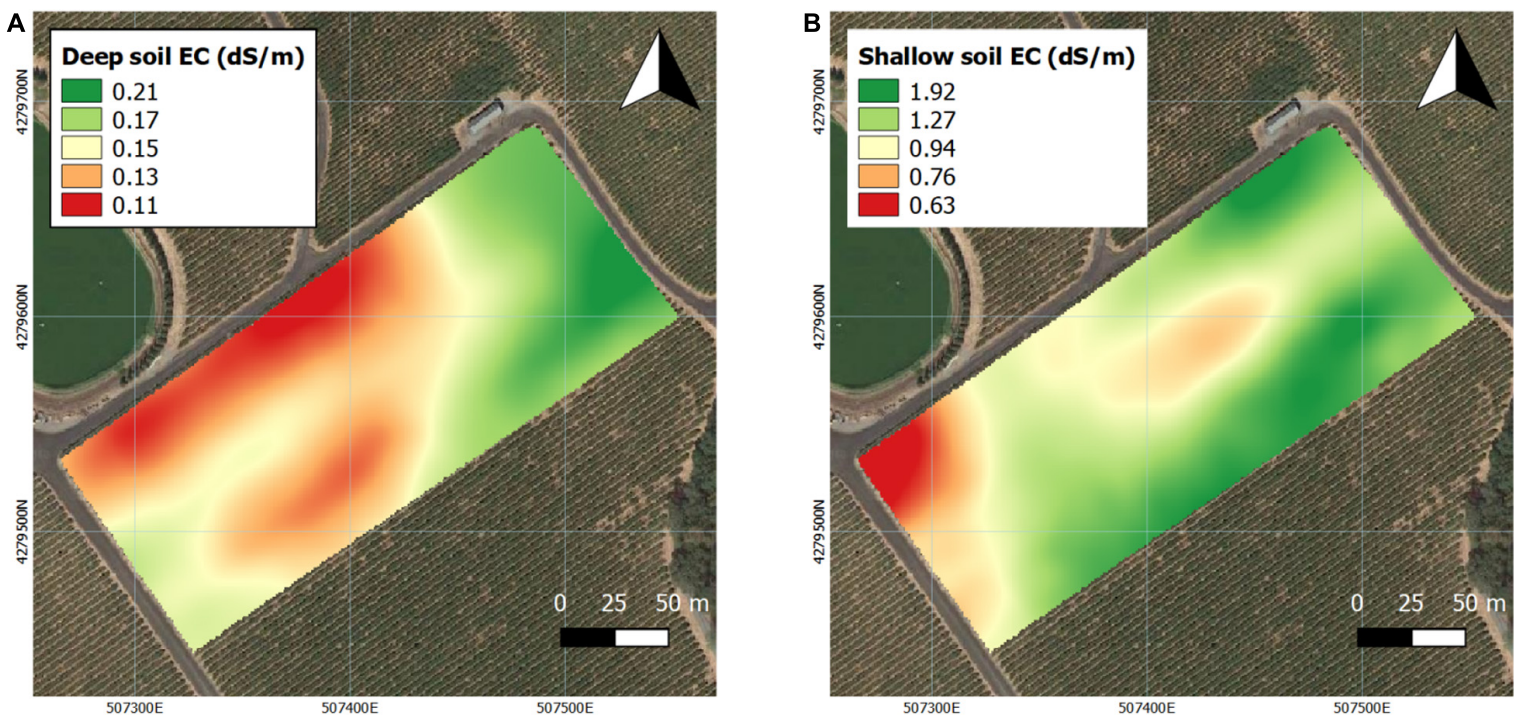

FIGURE 3 | Interpolation soil electrical conductivity (EC) in two depths assessed by EM38 in 2016 and 2017. (A) Deep soil (0-1.5 m), (B) shallow soil (0-0.75 m). Coordinate system: WGS 1984 UTM Zone $10 \mathrm{~N}$.

(Castellarin et al., 2007b; Martínez-Lüscher et al., 2014). Another major class in flavonoids, proanthocyanidins, are polymers of flavan-3-ol monomers and they contributes mainly toward astringency (tactile sensation) or bitterness (taste) in wine (Gonzalo-Diago et al., 2013). Compared to anthocyanins, water deficits showed mild effects on proanthocyanidins (Bucchetti et al., 2011). However, water deficits with great severity can still alter the concentration and composition of proanthocyanidins in both berries and wine (Ollé et al., 2011).

Selective harvest is one of the targeted management strategies to minimize the spatial variation in berry chemistry in vineyards
(Scarlett et al., 2014). By differentially harvesting or segregating the fruits into batches prior to vinification, the berry composition can be artificially set at a more uniform stage with minimal variations (Bramley et al., 2011b). In our previous work, we reported the use of plant water status to determine the spatial variation of grape berry flavonoids (Brillante et al., 2017). The goal of this study was to deduce if the spatial variability of soil bulk EC and differences in soil texture can be related to plant physiology and grape and wine composition. The specific objective of the study was to determine if the spatial variability of proximally sensed vineyard soil bulk EC would affect plant 

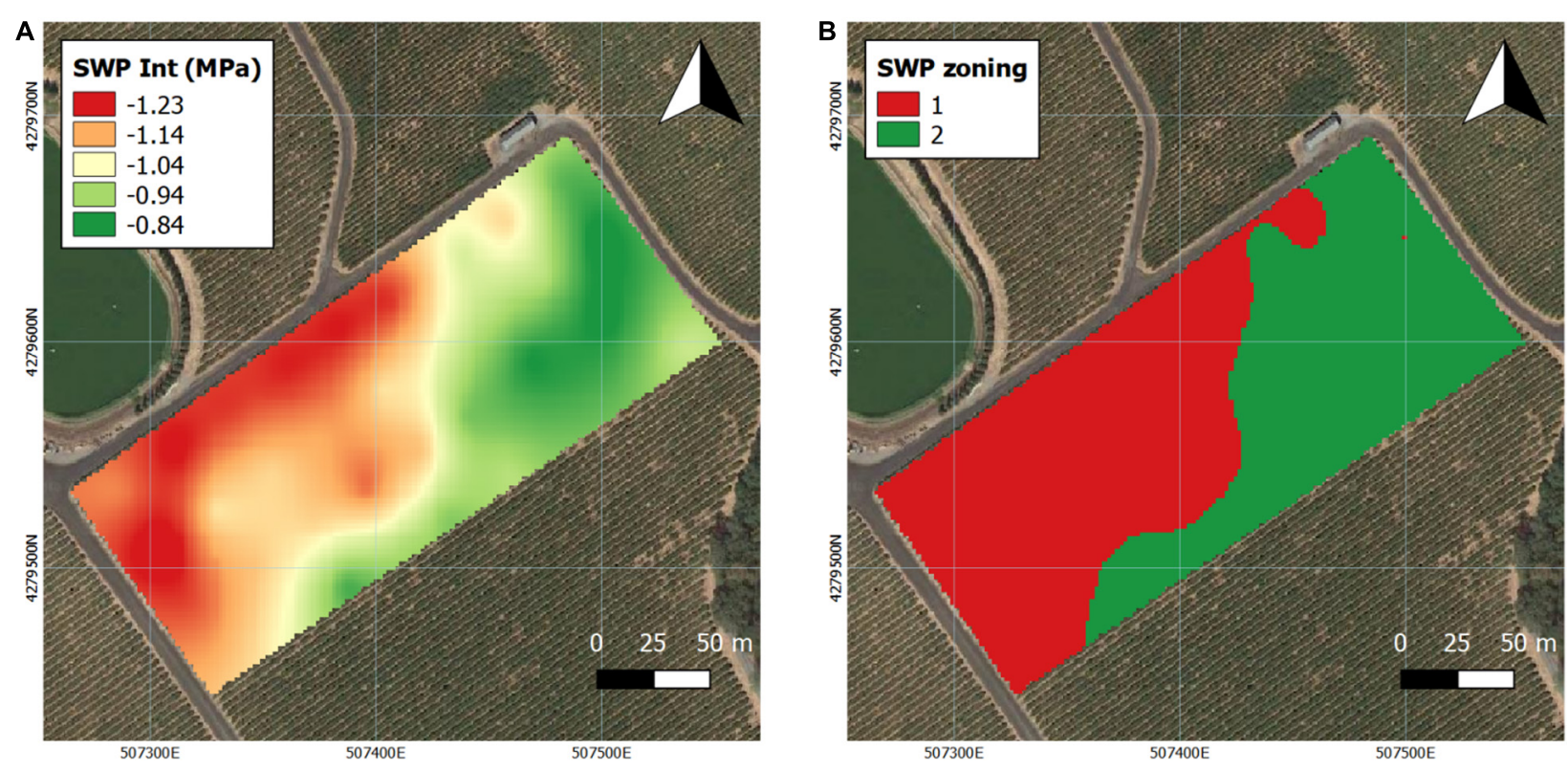

FIGURE 4 | Interpolation maps of plant water status (expressed as stem water potential $\Psi_{\text {stem }}$ ) and $k$-means clustering, delineating the vineyard into two zones in 2017. (A) $\Psi_{\text {stem }}$ kriging maps, (B) k-means clustering maps. Coordinate system: WGS 1984 UTM Zone 10N.

water status, and if this relation would affect leaf gas exchange, components of yield, berry composition, and flavonoids in both berries and wine.

\section{MATERIALS AND METHODS}

\section{Vineyard Site, Plant Materials, and Weather}

The study was conducted in a commercial vineyard in 2016 and 2017 with Cabernet Sauvignon (Vitis vinifera L.) grapevines grafted on 110R (Vitis berlandieri Planch. $\times$ Vitis rupestris Scheele) located in Healdsburg, CA, United States. In this vineyard, grapevines were planted at $1.83 \mathrm{~m} \times 3.35$ $\mathrm{m}$ (vine $\times$ row). The grapevines were trained to a highquadrilateral, horizontally split trellis with two bilateral cordons. They were spur pruned with two buds per spur, and seven spurs per meter of the cordon. Irrigation was applied uniformly with a drip irrigation system, starting at fruitset to the end of veraison at $50 \% \mathrm{ET}_{c}$. There were two emitters per grapevine, delivering $3.8 \mathrm{~L} \cdot \mathrm{h}^{-1}$ of water. Weather data was obtained from the California Irrigation Management Information System (CIMIS) station (\#86, Santa Rosa, CA, United States) to measure precipitation, air temperature, and reference evapotranspiration (Figure 1).

\section{Experimental Design}

An equidistant $33 \mathrm{~m} \times 33 \mathrm{~m}$ grid with 35 experimental units was used for on-site measurements and berry samplings. Each experimental unit consisted of five plants. The locations of each central plant in these five plant experimental units were registered as the grid nodes with a GPS (Yuma 2, Trimble Inc., Sunnyvale,
CA, United States), wirelessly connected to a Trimble Pro 6T DGNSS receiver (Trimble Inc., Sunnyvale, CA, United States).

\section{Vineyard Soil Property Assessment}

Soil bulk EC was assessed with EM38 (Geonics Ltd., Mississauga, ON, Canada) in 2016 when the vineyard soil was at field capacity condition. Both vertical dipole mode and horizontal dipole mode were used to assess EC at two depths, including deep soil (0-1.50 $\mathrm{m})$ and shallow soil $(0-0.75 \mathrm{~m})$. The instrument was calibrated according to manufacturer instructions. The device was placed on a PVC sled and driven through the vineyard with an allterrain vehicle along the inter-rows. A distance of approximately $0.5 \mathrm{~m}$ from the vehicle to the device was maintained to avoid interference with the vehicle. A stratified grid was used to collect soil samples corresponding to the two depths at which we measured soil bulk EC. Soil texture was assessed according to the soil analysis method: hydrometer analysis $(S-14.10)$ in the North American Proficiency Testing (NAPT) program.

\section{Grapevine Physiology Assessments}

Plant water status was assessed biweekly by midday stem water potential $\left(\Psi_{\text {stem }}\right)$ measurements. The measurements for $\Psi_{\text {stem }}$ in 2016 were previously described in 2016. In 2017, $\Psi_{\text {stem }}$ was assessed on 27 June, 13 July, 27 July, 8 August, 24 August, 8 September, and 19 September. The measurements were conducted at solar noon from 12:00 to 14:30 h. Three leaves from main shoot axes in the shade were selected and concealed in pinch-sealed Mylar ${ }^{\circledR}$ bags for $2 \mathrm{~h}$ prior to the measurements. A pressure chamber (Model 615D, PMS Instrument Company, Albany, OR, United States) was used to take the measurements. To summarize the season-long plant water status, $\Psi_{\text {stem }}$ integrals were calculated by using natural 


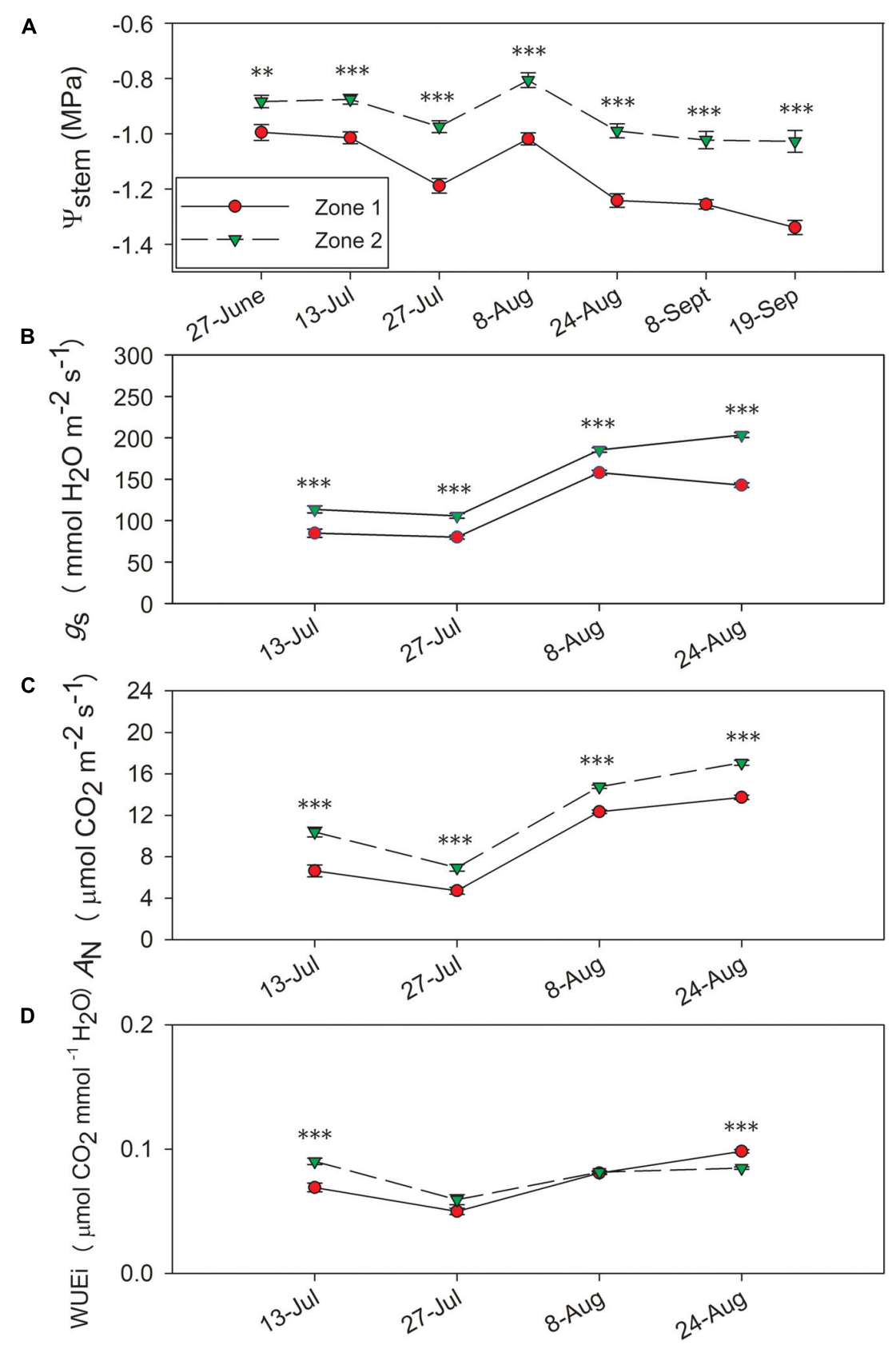

FIGURE 5 | Progression of stem water potential $\Psi_{\text {stem }}$ and gas exchange between the two water status zones in 2017 . (A) $\Psi_{\text {stem, }}$ (B) stomatal conductance, $g_{s}$, (C) net carbon assimilation, $A_{N}$, (D) intrinsic water use efficiency, WUEi. Error bars represent standard error of the mean. Asterisks represents significant levels $p$ : *** $p<0.001,{ }^{* *} p<0.01,{ }^{*} p<0.05$.

cubic splines, and then normalized by the number of days elapsed from the first measurement to the last.

Leaf gas exchange measurements were taken biweekly by using a portable infrared gas analyzer CIRAS-3 (PP Systems, Amesbury, MA, United States). The measurements for leaf gas exchange in 2016 were previously described in 2016. In 2017, leaf gas exchange was assessed on 13 July, 27 July, 8 August, and 24 August. The gas analyzer was set to a relative humidity of $40 \%$ and the reference $\mathrm{CO}_{2}$ concentration of $400 \mu \mathrm{mol}$
$\mathrm{CO}_{2} \cdot \mathrm{mol}^{-1}$. Three sun-exposed leaves from the main shoot axis were measured in each vine, and the three middle vines were selected in each experimental unit. Gas exchange measurements were taken when the sunlight was at saturation conditions in both years (average $\mathrm{PAR}_{i}=1969 \pm 135 \mu \mathrm{mol} \cdot \mathrm{m}^{-2} \cdot \mathrm{s}^{-1}$ in 2016 , $1884 \pm 165 \mu \mathrm{mol} \cdot \mathrm{m}^{-2} \cdot \mathrm{s}^{-1}$ in 2017).

Yield components were measured on a single harvest day in each season (5 October 2016 and 20 September 2017). The dates were chosen to follow the grower's harvest schedule. The clusters 


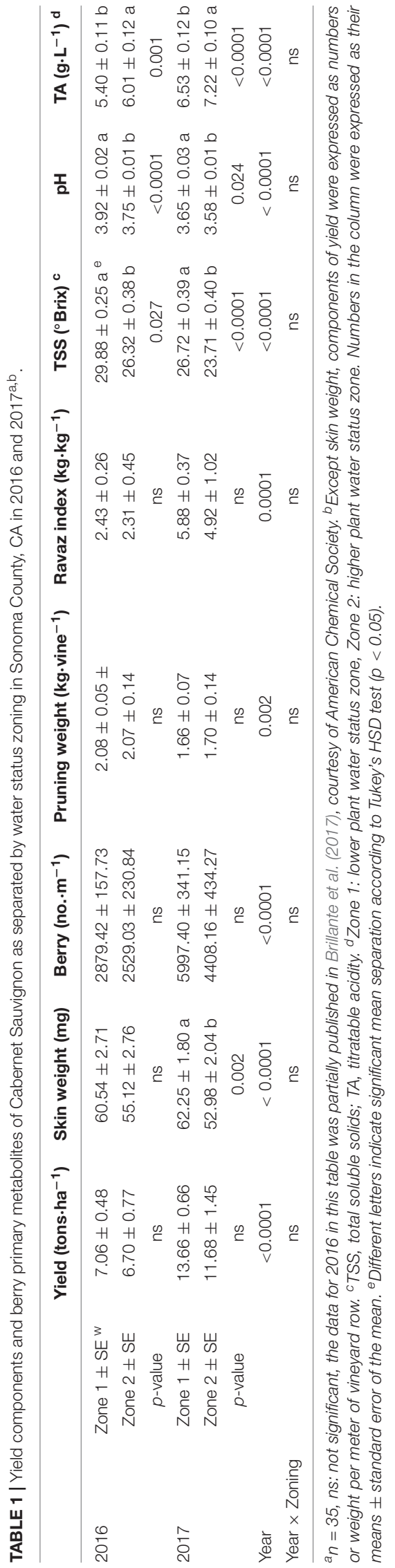

from the three middle vines in each experimental unit were harvested, counted, and weighed. Cluster weight was calculated by dividing crop weight by cluster number. A total of 75 berries were randomly selected from the five vines in each experimental unit, and were separated into two subsets of 55 and 20 berries. The first set with 55 berries was used for berry composition analysis. The second set with 20 berries was for measuring berry skin mass and skin flavonoid contents. The average berry weight were assessed from the average weight of the total 75 berries. Pruning weight per vine was collected during the dormant season. Ravaz index was calculated as the ratio of the yield per vine and the pruning weight per vine.

\section{Berry Total Soluble Solids, pH, and Titratable Acidity}

Berry samples were taken biweekly throughout each season. In 2016, berry wet chemistry was assessed on 15 July, 28 July, 11 August, 23 August, 1 September, 15 September, and 5 October. In 2017, berry wet chemistry was assessed on 13 July, 27 July, 8 August, 24 August, 7 September, and 20 September. Total soluble solids (TSS, measured $\mathrm{as}^{\circ} \mathrm{Brix}$ ), $\mathrm{pH}$, and titratable acidity (TA) were analyzed on the must. Berry TSS were measured by a digital refractometer (Atago PR-32, Bellevue, WA, United States). Must $\mathrm{pH}$ and TA (expressed as $\mathrm{g}$ of tartaric acid per $\mathrm{L}$ of must after titration to $\mathrm{pH}$ 8.3) were measured with an automated titrator (862 Compact TitroSampler, Metrohm, Switzerland).

\section{Extraction of Skin Flavonoid Compounds}

Skins were manually peeled from the 20 berries with a scalpel, and lyophilized by a freeze-drier (Triad Freeze-Dry System, Labconco, Kansas City, MO, United States). Skin tissues were then powderized with a mixing mill (MM400, Retsch, Mammelzen, Germany). For anthocyanin analysis, $50 \mathrm{mg}$ of dry skin powder was weighed and extracted with $1 \mathrm{~mL}$ of methanol:water:7 M hydrochloric acid (70:29:1) solution at $4^{\circ} \mathrm{C}$ overnight. Extracts were centrifuged at 5,000 rpm for $10 \mathrm{~min}$, the supernatants were filtered by PTFE membrane filters (diameter: $13 \mathrm{~mm}$, pore size: $0.45 \mu \mathrm{m}$, VWR, Seattle, WA, United States), and transferred into high performance liquid chromatography system (HPLC) vials before injection.

\section{Berry and Wine Flavonoid Analysis}

Skin anthocyanins were analyzed by a reversed-phase HPLC (Agilent model 1260, Agilent Technologies, Santa Clara, CA, United States) consisting of a vacuum degasser, an autosampler, a quaternary pump, and a diode array detector with a column heater. A C18 reversed-phase column (LiChrosphere 100 RP-18, $4 \times 520 \mathrm{~mm}^{2}, 5 \mu \mathrm{m}$ particle size, Agilent Technologies, Santa Clara, CA, United States) was utilized for analyzing anthocyanins. The mobile phase flow rate was $0.5 \mathrm{~mL} \cdot \mathrm{min}^{-1}$, and two mobile phases were used, which included solvent $\mathrm{A}=5.5 \%$ aqueous formic acid $(\mathrm{v} / \mathrm{v})$ and solvent $\mathrm{B}=5.5 \%$ formic acid in acetonitrile (v/v). The HPLC flow gradient started with $91.5 \%$ A with $8.5 \%$ B; $87 \%$ A with $13 \%$ B at $25 \mathrm{~min}$; $82 \%$ A with $18 \%$ B at $35 \mathrm{~min}$; $62 \%$ A with $38 \%$ B at 70 mins; $50 \%$ A with $50 \%$ B at $70.01 \mathrm{~min}$; $30 \%$ A with $70 \%$ B at $75 \mathrm{~min}$; $91.5 \%$ A with $8.5 \%$ B from 


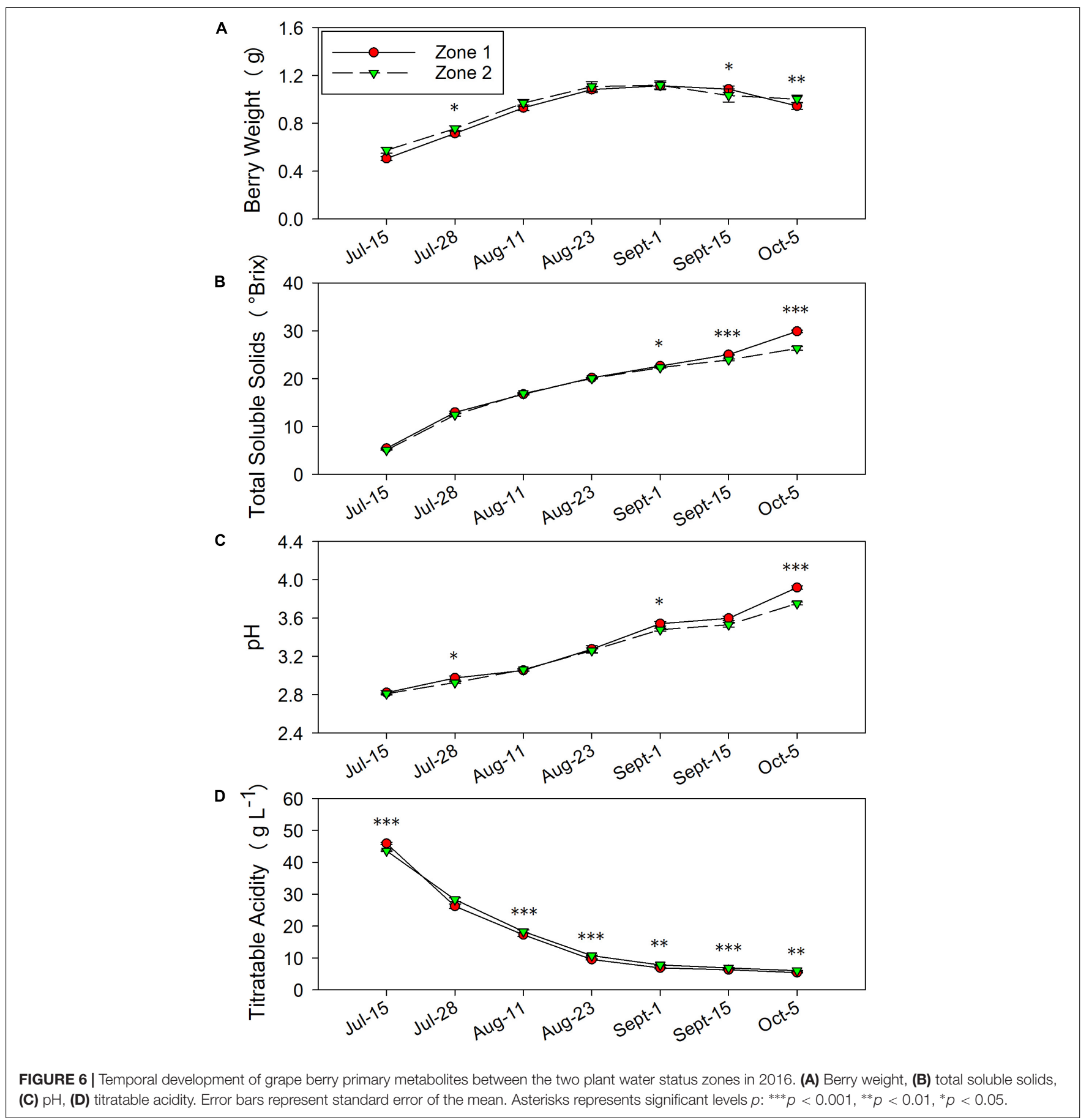

$75.01 \mathrm{~min}$ to $90 \mathrm{~min}$. The column temperature was maintained at $25^{\circ} \mathrm{C}$. Detection of anthocyanins was carried out by the diode array detector at $520 \mathrm{~nm}$. A computer workstation with Agilent OpenLAB (Chemstation edition, version A.02.10) was used for chromatographic analysis.

Wine proanthocyanidin subunits were characterized by acid catalysis in the presence of excess phloroglucinol by reversedphase HPLC (Agilent model 1100, Agilent Technologies, Santa Clara, CA, United States) (Kennedy and Jones, 2001). $1 \mathrm{~mL}$ of wine sample was applied to the Bond Elut $\mathrm{C} 18 \mathrm{OH}$ solid phase extraction cartridges (Agilent Technologies, Santa Clara, CA, United States) to purify wine proanthocyanidins. Eluents were evaporated and resuspended in $1 \mathrm{~mL}$ of methanol, and $0.25 \mathrm{~mL}$ methanolic extracts were combined with $0.25 \mathrm{~mL}$ of phloroglucinolysis reagent $\left(100 \mathrm{~g} \cdot \mathrm{L}^{-1}\right.$ phloroglucinolysis and $20 \mathrm{~g} \cdot \mathrm{L}^{-1}$ ascorbic acid with $0.2 \mathrm{~N} \mathrm{HCl}$ at methanol). The mixtures were then water bathed at $50^{\circ} \mathrm{C}$ for $20 \mathrm{~min}$. The reaction was stopped by mixing $200 \mu \mathrm{L}$ of the sample mixtures with $1 \mathrm{~mL}$ 


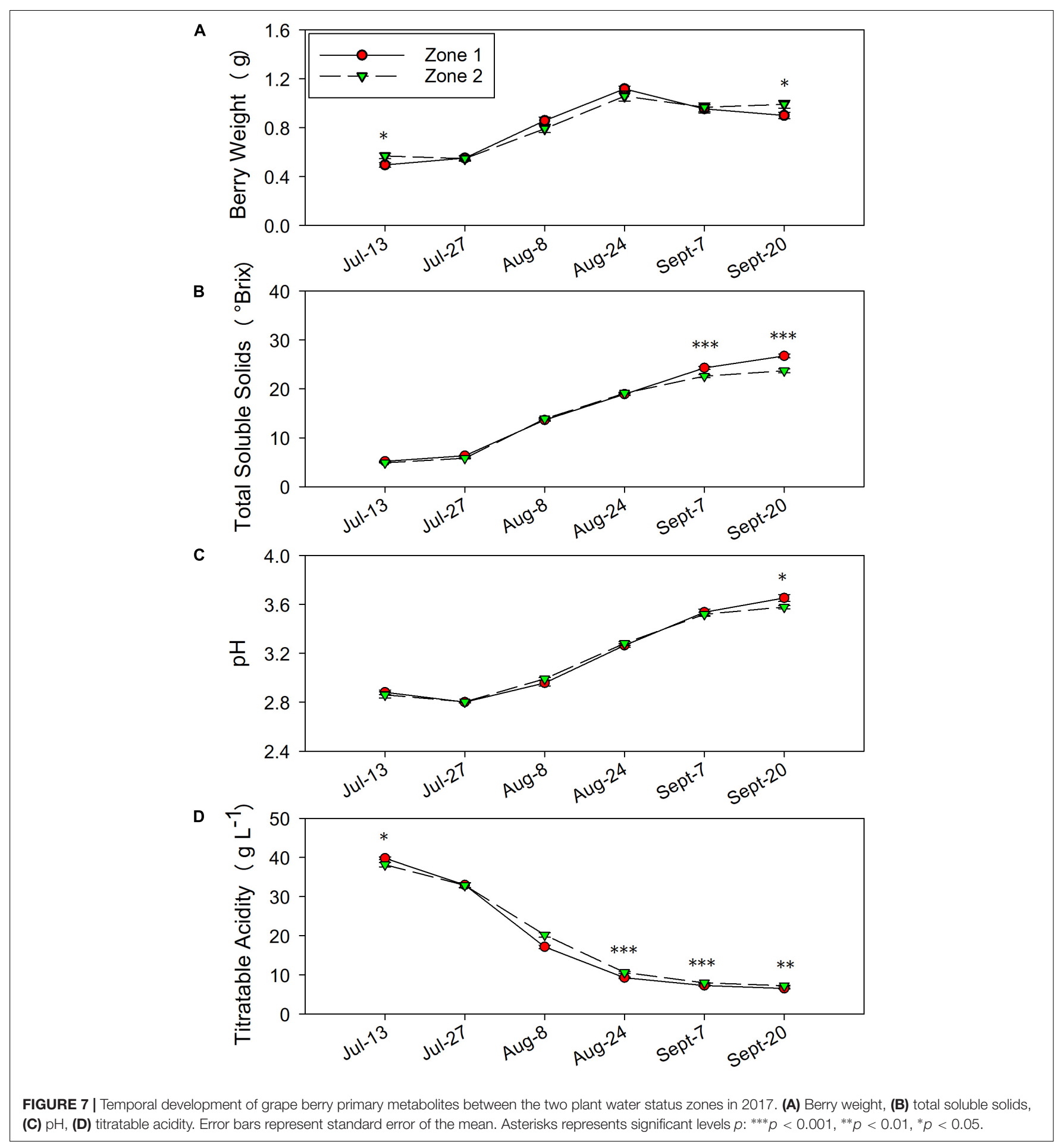

of stopping reagent ( $40 \mathrm{mM}$ aqueous sodium acetate) and then injected into the HPLC. The HPLC column consisted of two Chromolith RP-18e $\left(100 \times 4.6 \mathrm{~mm}^{2}\right)$ columns serially connected and protected by a guard column with the same material $(4 \times 4$ $\mathrm{mm}^{2}$ ) from EM Science (Gibbstown, NJ, United States). The mobile phase flow rate was $3.0 \mathrm{~mL} \cdot \mathrm{min}^{-1}$. Two mobile phases were used, which included solvent $\mathrm{A}=1 \%$ aqueous acetic acid (v/v) and solvent $B=1 \%$ acetic acid in acetonitrile (v/v). The HPLC flow gradient started with $97 \%$ A with $3 \% \mathrm{~B} ; 82 \% \mathrm{~A}$, $18 \% \mathrm{~B}$ at $14 \mathrm{~min} ; 20 \% \mathrm{~A}, 80 \% \mathrm{~B}$ at $14.01 \mathrm{~min} ; 97 \% \mathrm{~A}, 3 \% \mathrm{~B}$ at $16.01 \mathrm{~min}$ until $20 \mathrm{~min}$.

All solvents used in this analysis were of HPLC grade, including acetonitrile, methanol, hydrochloric acid, and formic acid purchased from Fisher Scientific (Santa Clara, CA, 

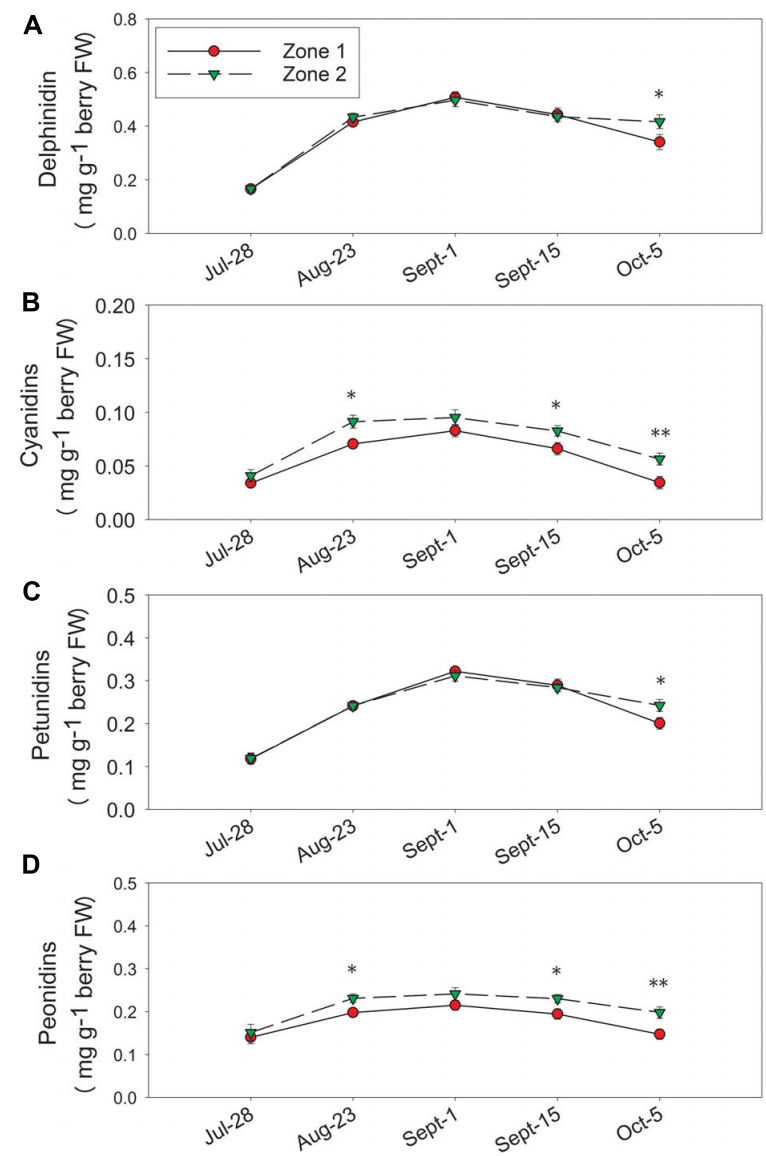
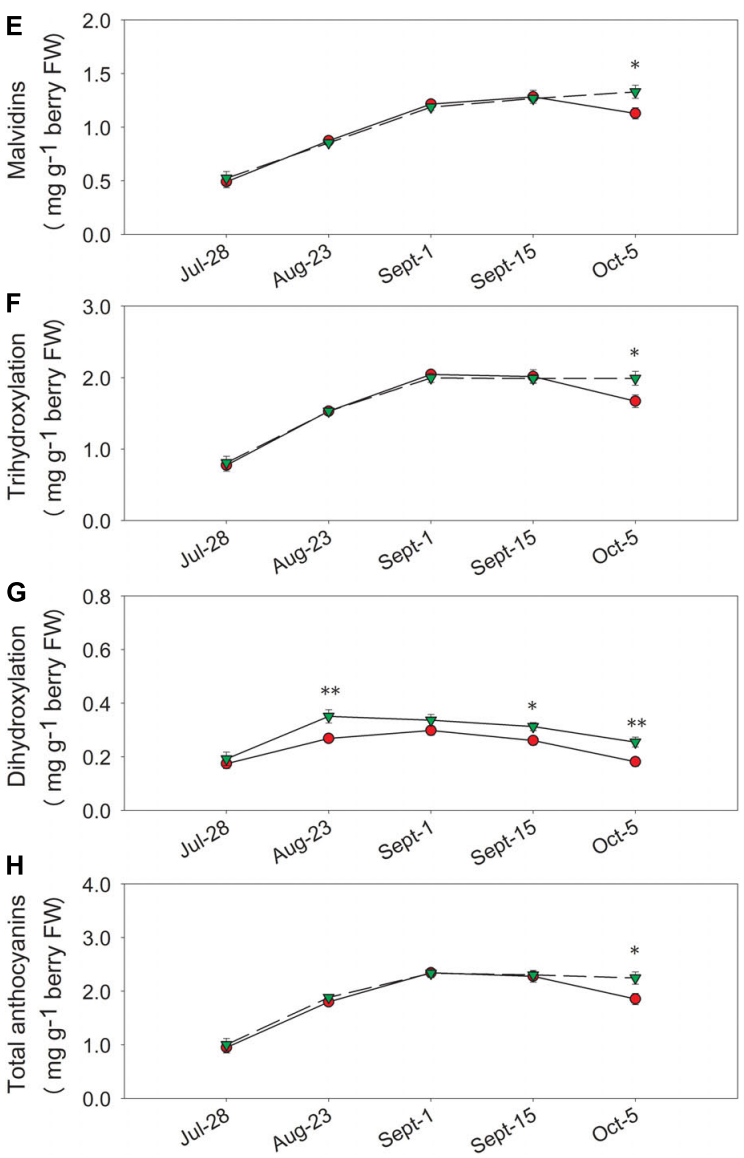

FIGURE 8 | Temporal development of grape berry anthocyanins between the two plant water status zones in 2016. (A) Delphinidins, (B) cyanidins, (C) petunidins, (D) peonidins, (E) malvidins, (F) tri-hydroxylation, (G) di-hydroxylation, (H) total anthocyanins. Error bars represent standard error of the mean. Asterisks represents significant levels $p:{ }^{* * *} p<0.001,{ }^{* *} p<0.01,{ }^{*} p<0.05$.

United States). Standards used for compound identification included malvidin 3-O-glucoside, (-)-epicatechin purchased from Extrasynthese (Genay, France). Phloroglucinol was purchased from VWR (Visalia, CA, United States).

\section{Statistical Analysis}

Geostatistical analysis was performed in the $\mathrm{R}$ language by using package "gstat" 1.1-6 (Pebesma, 2004). The bulk EC data were filtered by Tukey's rule to remove outliers either below the first quartile by 1.5 inter-quartile range or above the third quartile by 1.5 inter-quartile range. To further remove the outliers, the data were filtered by the speed that the vehicle was driving, which was between $3.2 \mathrm{~km}$ per hour to $8.0 \mathrm{~km}$ per hour. Variograms were assessed by “automap" package 1.0-14 (Hiemstra, 2013), and fitted to perform kriging. The soil bulk EC values were extracted from the location of each experimental unit, these values were further used to perform regression analysis. Kriging and $k$-means clustering on plant physiology variables were performed with the R packages "gstat" and "NbClust," v3.0 (Charrad et al., 2014). Universal kriging was utilized on plant water status because of the existing trend in longitude and latitude. Variograms were assessed by "automap" package 1.0-14 (Hiemstra, 2013), and fitted to perform universal kriging. The vineyard was delineated into two clusters by $k$-means clustering, including Zone 1 with higher water deficit and Zone 2 with lower water deficits. The separation described $78.1 \%$ in 2017 of the variability in the plant water status according to the result of between sum of squares/total sum of squares. The resulting maps were organized and displayed by using QGIS software (version 2.14.12, QGIS Development Team). Cluster comparison was analyzed by "raster" package reported as Pearson's Correlation between two cluster maps (Hijmans et al., 2015).

Data were tested for normality by using Shapiro-Wilk's test, and subjected to mean separation by using two-way ANOVA with the package "stats" in RStudio (R Foundation for Statistical Computing, Vienna, Austria) (R Core Team, 2019). Significant statistical differences were determined when $p$ values acquired from ANOVA were $<0.05$, and the zones were classified according to Tukey's honestly significant difference (HSD) test. Regression analysis was performed by SigmaPlot 13.0 (Systat Software Inc., San Jose, CA, United States). Correlation coefficient between variables were calculated in by Pearson's correlation analysis, and $p$-values were acquired to present the significances of the linear fittings. 


\section{Winemaking Procedures}

Vinification was conducted in 2016 and 2017 at the UC Davis Teaching and Research Winery. The grapes were harvested when Zone 1 reached a TSS of $29.88^{\circ} \mathrm{Bx}, 3.92 \mathrm{pH}, 5.40 \mathrm{~g} \cdot \mathrm{L}^{-1}$ TA in 2016 and $26.72^{\circ} \mathrm{Bx}, 3.65 \mathrm{pH}, 6.53 \mathrm{~g} \cdot \mathrm{L}^{-1} \mathrm{TA}$ in 2017, and Zone 2 reached a TSS of $26.32^{\circ} \mathrm{Bx}, 3.75 \mathrm{pH}, 6.01 \mathrm{~g} \cdot \mathrm{L}^{-1}$ TA in 2016 and $23.71^{\circ} \mathrm{Bx}, 3.58 \mathrm{pH}, 7.22 \mathrm{~g} \cdot \mathrm{L}^{-1}$ TA in 2017. Before dividing the fruits from each zone into three dependent replicate fermentation vessels (200 L each), the grapes were destemmed and crushed once transported into the winery. $50 \mathrm{mg} \cdot \mathrm{L}^{-1}$ of $\mathrm{SO}_{2}$ was added to each vessel to prevent oxidation. Water was added to the musts to balance soluble solid level at $25^{\circ} \mathrm{Bx}$ due to the highly possible stuck fermentation events may occur based on the high TSS levels. Dilution factors were considered when analyzing the final wine chemical composition. The must samples were inoculated with EC1118 yeast (Lallemand Lalvin ${ }^{\circledR}$, Montreal, Canada) to initiate the fermentation in jacketed stainless steel tanks controlled by an integrated fermentation control system (T.J fermenters, Cypress Semiconductor Co., San Jose, CA, United States), and two volumes of must were pumped over twice per day by the system. The fermentations were carried at $25^{\circ} \mathrm{C}$ until the residual sugar contents were below $3 \mathrm{~g} \cdot \mathrm{L}^{-1}$. Malolactic fermentation was initiated with the addition of Viniflora ${ }^{\circledR}$ Oenococcus oeni (Chr. Hansen A/S, Hørsholm, Denmark) at $12^{\circ} \mathrm{C}$ and $60 \%$ humidity. The free $\mathrm{SO}_{2}$ levels were adjusted to $30 \mathrm{mg} \cdot \mathrm{L}^{-1}$ after malolactic fermentation completed. Then the wines were sterile filtered and bottled before further chemical analysis. Wine samples were filtered by PTFE membrane filters (diameter: $13 \mathrm{~mm}$, pore size: $0.45 \mu \mathrm{m}$, VWR, Seattle, WA, United States) and transferred directly into HPLC vials for anthocyanin analysis.

\section{RESULTS}

\section{Weather at the Research Site}

Between the 2 years of the study, the precipitation amounts were different (Figure 1A). The precipitation amount in the dormant season prior to 2016 was $559.5 \mathrm{~mm}$ (from previous harvest date to May as we reported previously; Brillante et al., 2017). However, this amount was $898 \mathrm{~mm}$ in the 2016-2017 season. The precipitation during growing seasons in these 2 years were limited, there were only $51.6 \mathrm{~mm}$ of precipitation received in 2016 from April to harvest. In 2017, $107 \mathrm{~mm}$ of precipitation were received from April to harvest. The research site only received $11.1 \mathrm{~mm}$ in 2016 and $15.4 \mathrm{~mm}$ in 2017 during the study time in each year from June to harvest. There was a slight difference observed close to harvest (Figure 1B). In 2016, GDD accumulation was $1183^{\circ} \mathrm{C}$ at harvest (5 October 2016). The GDD accumulation was greater in 2017 at $1220^{\circ} \mathrm{C}$ by harvest (20 September 2017). The cumulative $\mathrm{ET}_{o}$ was greater in 2017 compared to 2016 (Figure 1C). At harvest, the cumulative $\mathrm{ET}_{o}$ was $750 \mathrm{~mm}$ in 2016, but it was relatively lower compared to $872.8 \mathrm{~mm}$ in 2017 .

\section{Soil Property Assessment}

Soil texture was measured at two different depths (Figure 2). In deep soil, the majority of the westerly section of the vineyard consisted mostly of loam with a small portion of clay loam in the southwestern corner of the vineyard, with the remainder being characterized as sandy clay loam (Figure 2A). In shallow soil, the easterly section of the vineyard mainly was a sandy clay loam with loam comprising the rest of shallow soil of the vineyard (Figure 2B).

Soil bulk EC was also assessed at two different depths by proximal sensing in the first season (Figure 3). In deep soil, EC values were lower in the majority of the westerly section of the vineyard (Figure 3A). In shallow soil, EC values were lower in the northwestern corner of the vineyard, and a small portion of the central section also showed lower EC values (Figure 3B).

\section{Plant Water Status and Leaf Gas Exchange}

$\Psi_{\text {stem }}$ was continuously measured as previously reported in 2016 (Brillante et al., 2017) and 2017. Based on the interpolation of $\Psi_{\text {stem }}$, the trends in the calculated long-term $\Psi_{\text {stem }}$ integral maps were similar to the trends in the soil bulk EC maps, especially when compared to the deep EC map (Figure 4). Majority of the westerly section of the vineyard had more water stress in 2016 (Brillante et al., 2017) as well as in 2017 (Figure 4A). Then, the interpolation maps of the $\Psi_{\text {stem }}$ were separated into two zones by $k$-means clustering analysis as Year 1 was reported previously (Brillante et al., 2017). When comparing the two $k$-means clustering maps between 2016 and 2017, there was an $85 \%$ similarity according to Pearson's correlation coefficient between the two maps (Figure 4B). In 2017, the clustering map was 70 and $78 \%$ similar to the deep soil and shallow soil texture maps.

In 2017, $\Psi_{\text {stem }}$ were consistently different between the two zones (Figure 5A), where Zone 2 consistently had higher $\Psi_{\text {stem }}$ than Zone 1. $\Psi_{\text {stem }}$ values became more negative with the progression of time, and the differences in $\Psi_{\text {stem }}$ intensified throughout each season as berries reached a more advanced maturity. The differences between two zones ranged from $0.11 \mathrm{MPa}$ on the first measurement day of 27 June to $0.31 \mathrm{MPa}$ on the harvest day of 20 September. Between the two zones, a $0.22 \mathrm{MPa}$ differences in $\Psi_{\text {stem }}$ integrals were observed in 2017, similar to $0.21 \mathrm{MPa}$ as in 2016 (Brillante et al., 2017).

Leaf gas exchange was measured 2017, where both years showed evident differences between the zones in both $A_{n}$ and $g_{s}$ (Figure 5). In 2017, the two zones showed significant differences in $A_{n}$ and $g_{s}$ with the highest values observed on 24 August (Figures 5B,C). Conversely, there was no consistent difference in $\mathrm{WUE}_{i}$ between the two zones in 2017, except Zone 2 showed higher WUEi on 13 July and lower WUEi on 24 August (Figure 5D).

\section{Yield Components, Must Soluble Solids, $\mathrm{pH}$, and Titratable Acidity}

Components of yield were measured at harvest (Table 1, the harvest data on 5 October 2016 was reported previously in 
Brillante et al., 2017), and berry primary metabolites were continuously assessed during 2016 and 2017 (Figures 6, 7, the harvest data on 5 October 2016 was reported previously in Brillante et al., 2017). Between the two plant water status zones, there was no differences in yield, berry number, pruning weight, or Ravaz Index. However, there was an effect of experimental year where we measured greater yield and lower pruning weight per vine in Year 2. The only difference observed in yield components was that the berry skin weights were greater in Zone 1 in 2017.

The berry primary metabolites were different between the two zones in both years of the study. In 2016, berry weights were greater in Zone 2 on 28 July and 5 October when the fruits were harvested (Figure 6A). Zone 1 showed higher berry weights on 15 September. When the irrigation was stopped at veraison, TSS were higher in Zone 1 compared to Zone 2, which was measured on 1 September, 15 September, and 5 October (Figure 6B). At harvest, the fruits in Zone 1 reached a TSS of $29.9^{\circ} \mathrm{Bx}$, while the ones in Zone 2 reached $26.3^{\circ} \mathrm{Bx}$. The juice $\mathrm{pH}$ showed a similar result with TSS, where Zone 1 had higher $\mathrm{pH}$ in the last 3 months before harvest, except there was no difference shown on 15 September (Figure 6C). Berry TA was consistently higher in Zone 2 on all measured dates except 28 July (Figure 6D). At harvest, Zone 2 had $6.0 \mathrm{~g} \cdot \mathrm{L}^{-1}$ of TA, Zone 1 had $5.4 \mathrm{~g} \cdot \mathrm{L}^{-1}$.

In 2017, the differences in TSS, $\mathrm{pH}$ and TA were similar to 2016. Berry weights were higher in Zone 2 on 13 July and at harvest on 20 September (Figure 7A). The TSS increased more rapidly in Zone 1 close to harvest on 7 September and 20 September (Figure 7B) when compared to Zone 2. At harvest, TSS values were slightly lower than 2016 due to an earlier harvest time, where Zone 1 reached a TSS of $26.7^{\circ} \mathrm{Bx}$, while Zone 2 reached $23.7^{\circ} \mathrm{Bx}$ (Table 1). The juice $\mathrm{pH}$ was higher in Zone 1 than Zone 2 at harvest as well (Figure 7C). Similar to 2016, the TA in the two zones was consistently different where Zone 2 had higher TA than Zone 1 on starting on 24 August until harvest (Figure 7D). At harvest, Zone 2 had $7.2 \mathrm{~g} \cdot \mathrm{L}^{-1}$ of TA, Zone 1 had $6.5 \mathrm{~g} \cdot \mathrm{L}^{-1}$.

\section{Berry Skin Anthocyanins at Harvest}

Berry skin anthocyanins were different between the two zones in 2016 (the harvest data on 5 October 2016 was partially reported previously in Brillante et al., 2017). Total delphinidins, petunidins, malvidins, and the sum of them as trihydroxylated anthocyanins were all higher in Zone 2 than Zone 1 (Figures 8A,C,E,F,H). Total cyanidins, peonidins, and the sum of them as di-hydroxylated anthocyanins were greater in Zone 2 on 23 August, 15 September, and at harvest (Figures 8B,D,G). Total skin anthocyanins were $2.2 \mathrm{mg}$ per g of berry fresh weight (FW) in Zone 2 which was higher than the $1.85 \mathrm{mg}$ measured in Zone 1 (Table 2).

In 2017, there were no differences between the two zones in delphinidin, cyanidin, petunidin, or peonidin at harvest (Figures 9A-D). Zone 1 had higher malvidins from 24 August until harvest, and tri-hydroxylated anthocyanins, total anthocyanins from 7 September until harvest (Figures 9E,F,H). Conversely, total malvidins, tri-hydroxylated anthocyanins, and total anthocyanins were higher in Zone 1 at harvest (Table 2). In Zone 2, we measured higher cyanidins and di-hydroxylated

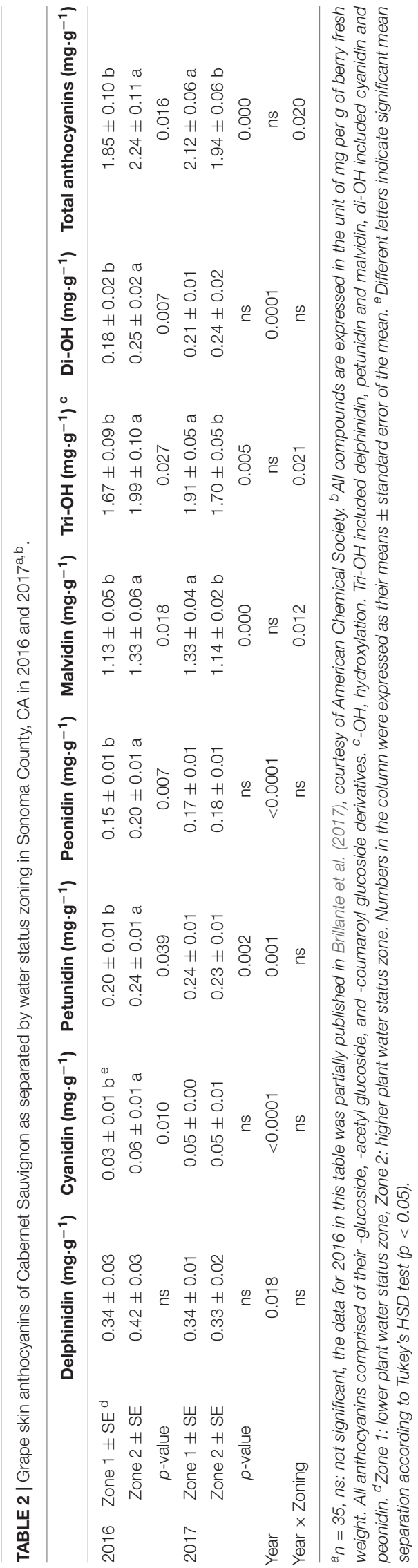



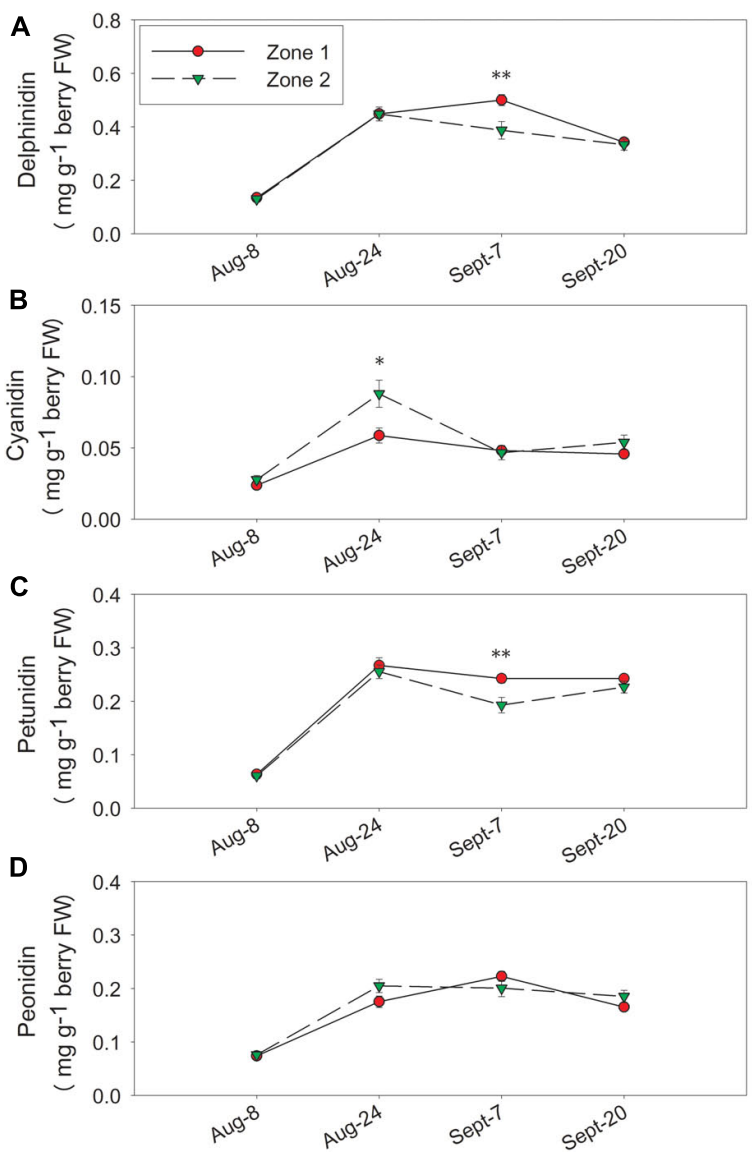
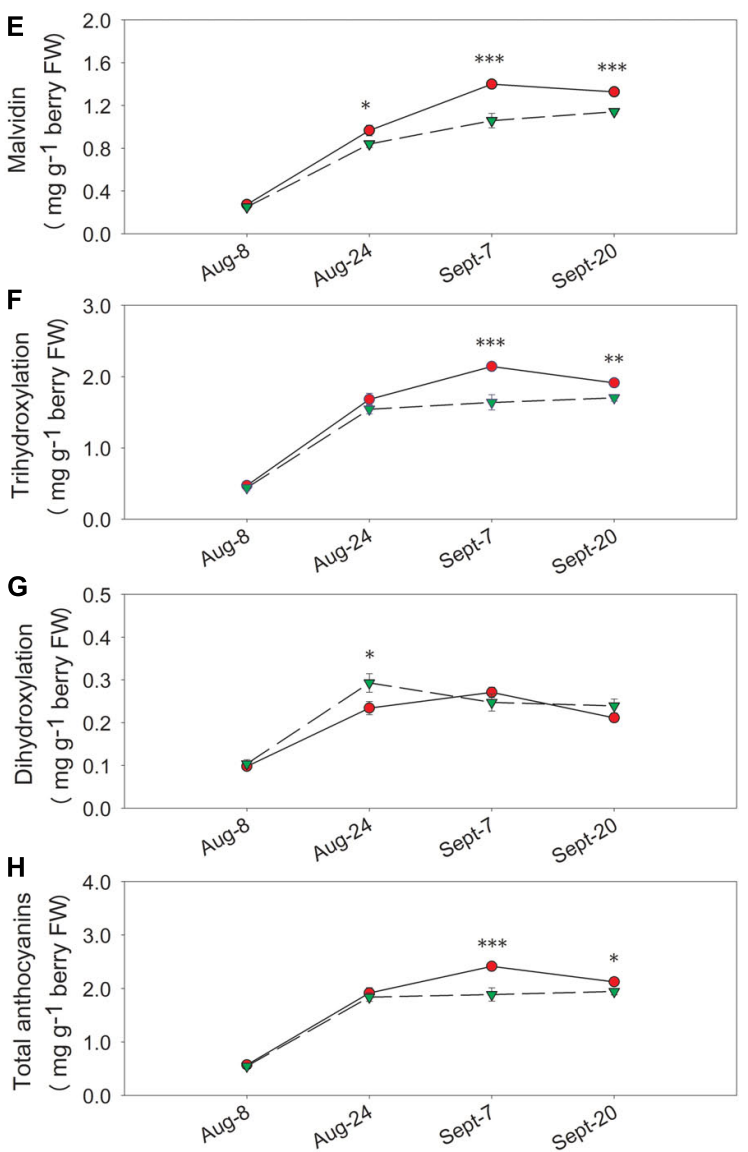

FIGURE 9 | Temporal development of grape berry anthocyanins between the two water status zones in 2017. (A) Delphinidins, (B) cyanidins, (C) petunidins, (D) peonidins, (E) malvidins, (F) tri-hydroxylation, (G) di-hydroxylation, $(\mathbf{H})$ total anthocyanins. Error bars represent standard error of the mean. Asterisks represents significant levels $p$ : ${ }^{* * *} p<0.001,{ }^{* *} p<0.01,{ }^{*} p<0.05$.

anthocyanins on 24 August (Figures 9B,G), and that was the only date Zone 2 had higher concentrations in any of these derivatives.

The temporal relationships between TSS and berry skin anthocyanins were investigated in both years (Figure 10). In both years, skin anthocyanins increased with the accumulation of TSS at first. In 2016, berry anthocyanins of Zone 1 had a significant decline in skin anthocyanins after $25^{\circ} \mathrm{Bx}$ TSS, resulting a lower concentration when compared to Zone 2 (Figure 10A). Conversely, the second season consistently showed greater anthocyanin concentration in Zone 1 than Zone 2 (Figure 10B). However, Zone 1 showed a more rapid decline after around $25^{\circ} \mathrm{Bx}$ TSS, and the skin anthocyanins were similar in values with Zone 2.

\section{Wine Flavonoids}

Wine-free anthocyanins and proanthocyanidins were assessed in both years. For anthocyanins, Zone 2 had higher concentrations of all derivatives in 2016, including tri-, di- hydroxylated, and total anthocyanins (Table 3). All the compounds were more than two times greater than Zone 1. However, there was no difference observed in any of these compounds in 2017. The overall concentrations of all these compounds were greater in 2017 than 2016.

For proanthocyanidins, similar results were observed (Table 4). In 2016, all the extension and terminal subunits were higher in Zone 2 than Zone 1. The amount of total proanthocyanidins were also higher in Zone 2. In 2017, however, there was no difference observed in any of these subunits or total proanthocyanidins. Again, the second season showed greater concentrations in all of these compounds compared to the first season. Neither year showed difference in $\mathrm{mDP}$ between the two zones.

\section{Linking Soil to Grapevine Physiology}

The relationships between soil bulk EC and whole grapevine physiology were investigated (Table 5). Soil bulk EC values at both depths increased when $\Psi_{\text {stem }}$ became more positive, and soil bulk EC and $\Psi_{\text {stem }}$ were significantly correlated in both seasons. The relationships between soil bulk EC and TSS reflected the relationships between soil bulk EC and $\Psi_{\text {stem }}$. They showed significant relations with each other in both years. In $2016, \Psi_{\text {stem }}$ showed a positive relationship with berry weight at harvest. No significant correlation was observed between soil bulk EC and 


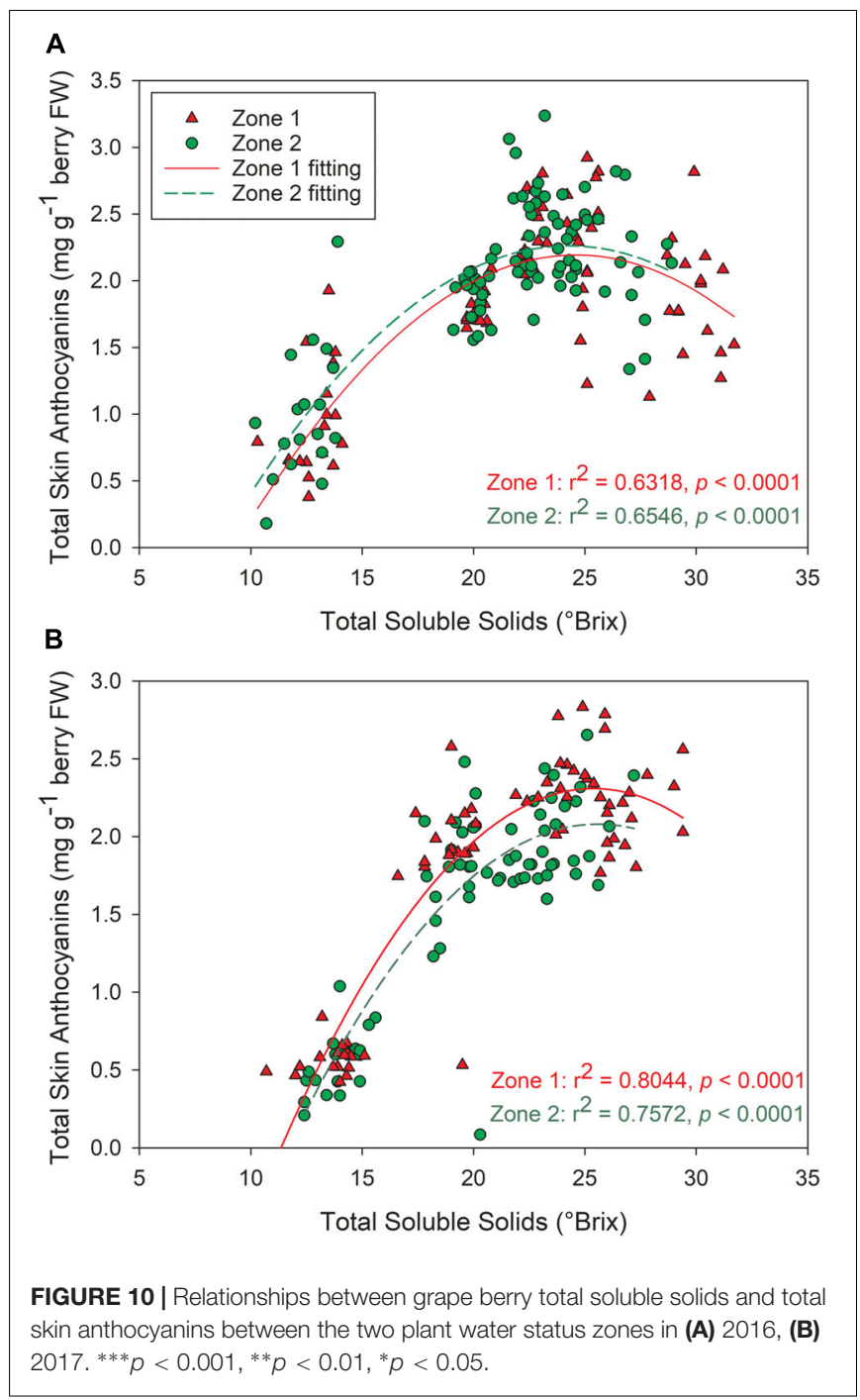

berry weight. However, shallow soil bulk EC showed a positive correlation with berry weight besides $\Psi_{\text {stem }}$ in 2017 . Berry skin weight and total anthocyanins did not have any significant relationships with neither $\Psi_{\text {stem }}$ nor soil bulk EC in 2017. In the same year, both berry skin weight and total anthocyanins were positively correlated with $\Psi_{\text {stem }}$, deep EC, and shallow EC. No parameters related to final yield except deep EC had a positive relationship with it in 2017.

\section{DISCUSSION}

\section{Soil Bulk EC and Plant Water Status Spatial Relationships}

Site topography influences plant water status (Brillante et al., 2017). In our previous work, we reported that absolute elevation of a vineyard was directly related to $\mathrm{Y}_{\text {stem }}$. The correlation between $\mathrm{Y}_{\text {stem }}$ and elevation was significant and negative, indicating that the $\mathrm{Y}_{\text {stem }}$ would be lower when the elevation was higher. When soil moisture was model as wetness index,

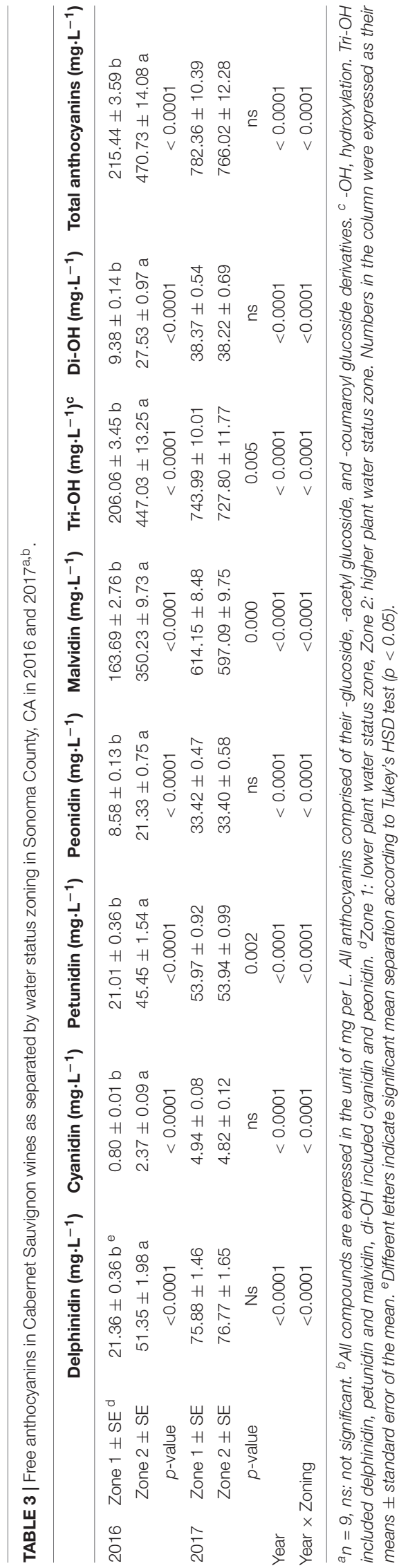




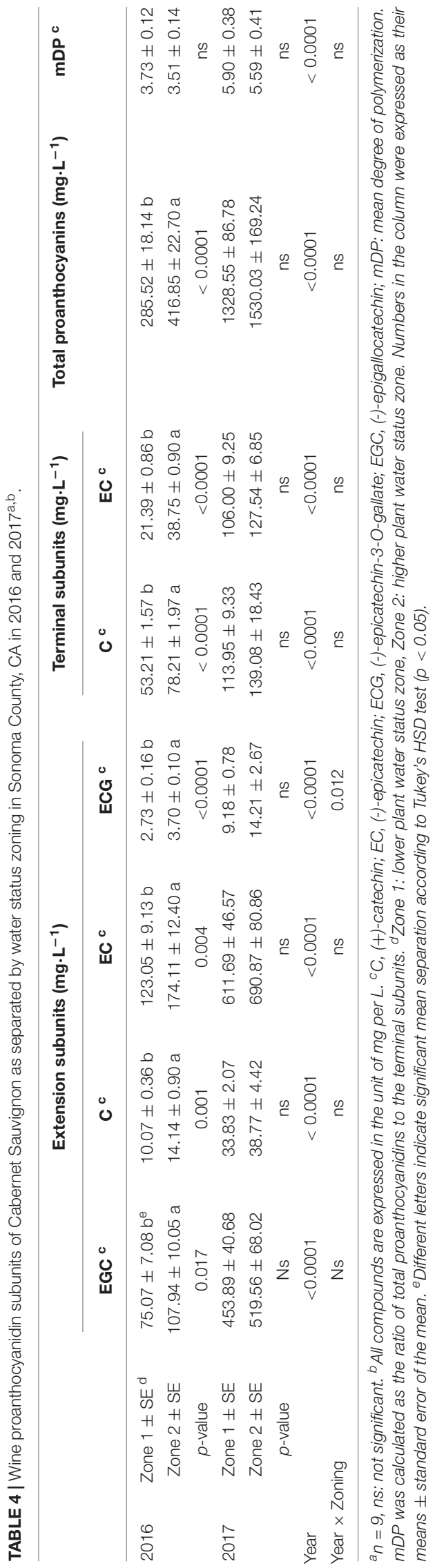

it indicated a negative and significant relationship with $\mathrm{Y}_{\text {stem }}$ but the relationship was not linear. In our previous work, we were unable to deduce a significant relationship between site topography variables such as absolute elevation and berry chemistry (Brillante et al., 2017). Bramley et al. (2011a) showed that soil bulk EC was directly related to soil clay content, which was contradictory to our findings. We attributed this discrepancy to the relatively stable soil texture throughout the season or even several seasons. On the other hand, the effect of soil water content might be the major factor to influence plant development during the season. The soil texture and soil bulk EC sensing analysis conducted in this study were able to explain the variability in plant water status that the site topography could not. Soil texture and soil bulk EC can be related to spatial differences in soil water availability (Tramontini et al., 2013). Specifically, soil texture is a determinant of soil water holding capacity, hence affecting the amount of water available to the plants. In our study, the western section of the vineyard had greater loam proportion, where the grapevines were experiencing more severe water deficits (Brillante et al., 2017). The eastern section had more sandy soil in both deep and shallow soil, where the grapevines were under less severe water deficits. Our findings are corroborated with previous work, where clay soil would lead to less plant available water, although clay soil had higher water holding capacity than sandy soil (Tramontini et al., 2013). Furthermore, Cabernet Sauvignon grapevines grown in clay soil would result in lower $g_{s}$ and $A_{n}$ compared to grapevines grown in soils that had higher proportion of sandy soils (Yu and Kurtural, 2020).

There was evident variability in soil bulk EC in this study. Previous studies reported that when soil bulk EC was proximally sensed, it was closely related to soil water content (Bittelli, 2011; Brillante et al., 2015). We found that soil bulk EC was consistently and directly related to long-term $\Psi_{\text {stem }}$ over the course of our study. Our findings are corroborated by previous works (Rodríguez-Pérez et al., 2011; Brillante et al., 2014), where higher soil bulk EC values corresponded to higher soil water content. Previous studies suggested that the relationship between soil water content and soil bulk EC was soil-specific, and needed to include soil chemical and physical properties to explain variability and plant water status (Morari et al., 2009; Brillante et al., 2016b). Due to the limited amount of water put into wine grape vineyards, soil water content would be the major factor affecting soil electrical properties rather than the residual salinity after water evaporation from soil. The significant relationship between soil bulk EC and $\Psi_{\text {stem }}$ in this study agreed with previous studies, indicating the possibility of soil bulk EC sensing being used to assess plant water status (Bramley et al., 2011a; Rodríguez-Pérez et al., 2011). Moreover, in our study, the spatial variability in grapevine physiology reflected the variability in soil bulk EC very well when assessed by proximal sensing. Due to the relationship of soil bulk EC on the amount of available water to plants reported in previous research (Rodríguez-Pérez et al., 2011; Brillante et al., 2014), this approach had been utilized to identify the variability in the plant physiology based on the soil sensing technologies and apply targeted management strategies (Bramley et al., 2011a), and our study provided more evidence toward the feasibility of it. 


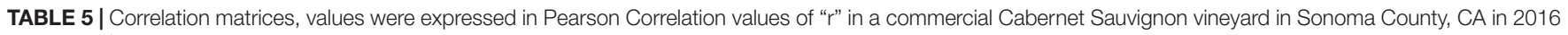
and $2017^{\mathrm{a}, \mathrm{b}}$.

\begin{tabular}{|c|c|c|c|c|c|c|c|c|c|}
\hline & & SWP Int & Deep EC & Shallow EC & TSS & Berry weight & Skin weight & TSA & Yield \\
\hline \multirow[t]{3}{*}{2016} & SWP Int & & $0.6^{\star \star \star C}$ & $0.68^{\star \star \star}$ & $-0.81^{\star \star \star}$ & $0.46^{\star \star}$ & 0.22 & 0.24 & 0.19 \\
\hline & Deep EC & $0.6^{\star \star \star}$ & & $0.5^{\star \star}$ & $-0.69^{\star \star \star}$ & 0.03 & 0.07 & 0.24 & 0.17 \\
\hline & Shallow EC & $0.68^{\star * \star}$ & $0.5^{\star \star}$ & & $-0.57^{\star \star \star}$ & 0.25 & 0.22 & 0.27 & 0.06 \\
\hline \multirow[t]{3}{*}{2017} & SWP Int & & $0.73^{\star \star \star}$ & $0.59^{\star \star \star}$ & $-0.83^{\star \star \star}$ & $0.49^{\star \star}$ & $0.49^{\star \star}$ & $0.6^{\star \star \star}$ & 0.20 \\
\hline & Deep EC & $0.73^{\star \star \star}$ & & $0.5^{\star \star}$ & $-0.68^{\star \star \star}$ & 0.18 & $0.35^{\star}$ & $0.53^{\star \star}$ & $0.41^{*}$ \\
\hline & Shallow EC & $0.59^{\star \star \star}$ & $0.5^{\star \star}$ & & $-0.67^{\star \star \star}$ & $0.51^{\star \star}$ & $0.55^{\star \star}$ & $0.39^{\star}$ & 0.02 \\
\hline
\end{tabular}

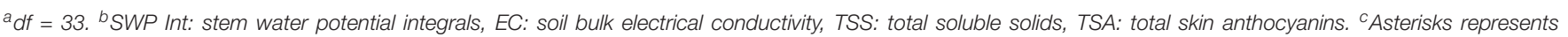
significant levels $p:{ }^{* * *} p<0.001,{ }^{* *} p<0.01,{ }^{*} p<0.05$.

The variability we measured proximally in soil characteristics was reflected in plant water status and leaf gas exchange in our study. Previous research had reported that variable soil characteristics in space would cause spatial variations in plant water status (Brillante et al., 2016a). Although the precipitation amounts were vastly different between the two dormant seasons, the uniformly scheduled irrigation did not ameliorate the natural spatial variability in plant water status induced by soil properties. On the contrary, the separations in plant water status and leaf gas exchange were already significant even before the irrigation ceased after veraison. This proved that the spatial variability in the soil dominated the accessibility of the available soil water toward the plant, and made the spatial variability expressed in the grapevine. Our results in the second year corroborated those of the first year, showing that the separation in both plant water status and leaf gas exchange between the two zones were consistent.

Leaf gas exchange was closely related to plant water status, and this relationship was shown in previous research (Costa et al., 2012). The relationships between leaf gas exchange and plant water status were evident in our study, where a higher $\Psi_{\text {stem }}$ would promote a greater stomatal conductance to increase carbon assimilation capacity and decrease intrinsic water use efficiency. In our study, the lowest $\Psi_{\text {stem }}$ we observed were around harvest with $\Psi_{\text {stem }}$ of $-1.6 \mathrm{MPa}$ and $g_{s}$ of around $50 \mathrm{mmol}$ $\mathrm{H}_{2} \mathrm{O} \mathrm{m} \mathrm{m}^{-2} \cdot \mathrm{s}^{-1}$, which were not severe enough to impair berry ripening although the photosynthetic activities were still affected. Overall, the $g_{s}$ and $A_{N}$ reached the maximum values at veraison and declined with decreasing plant water status and leaf age toward the end of the season. This further affirmed that the continuous water deficits during the growing season, especially being more pronounced after irrigation was ended after veraison, would reduce stomatal conductance. The water deficits would act as passive hydraulic signals or active hormonal signals with the upregulation in abscisic acid (ABA) synthesis to limit plant photosynthetic activities, hence lower $g_{s}$ and $A_{N}$ values (Costa et al., 2012; Tombesi et al., 2015).

\section{Components of Yield}

According to the previous research, components of yield may be affected by plant water status, where higher water deficits would result in reductions of yield, berry skin weight, and berry weight (Williams, 2010; Korkutal et al., 2011; Santesteban et al., 2011). In our study, we observed constant separation in plant water status after veraison. However, there was no difference shown in cluster number, yield, berry number, or pruning weight. The only difference measured in yield components was that berry skin weight was higher in Zone 1 in the second season. Early season water deficit irrigation (prior to veraison) had higher probability to decrease yield than later season water deficit irrigation (post-veraison to harvest). However, a season-long water deficit irrigation would have the lowest yield even despite the season-long water deficit irrigation regime applying double amount of water than the other regimes (Tarara et al., 2011). Some other studies did not have the same results, as early water deficit irrigation did not show significant influences on yield compared to late water deficit irrigation (Intrigliolo and Castel, 2010; Intrigliolo et al., 2012). Another possible explanation was that Zone 1 had greater water amount held in the soil due to the higher clay content. The clay soil with higher water-holding capacity had a better water status at the early season compared to Zone 2, even though the sandy soil in Zone 2 would benefit the plant growth with irrigation when the season progressed (Tramontini et al., 2013). The later season water deficit was exacerbated in Zone 1 due to its higher clay content, causing Zone 1 lost the benefits from the high water status in the early season, and eventually had similar yield components with Zone 2 at harvest. In our work, we did not see any evidence of Ravaz index being affected by spatial variability of plant water status. These results were corroborated by Terry and Kurtural when grapevine cultivar 'Syrah' was exposed to post-veraison water deficits in comparable severity of -1.4 MPa (Terry and Kurtural, 2011).

\section{Must-Soluble Solids, pH, and Titratable Acidity}

Water deficits affect advancement of grape berry maturity, they promote TSS accumulation and TA degradation in grape berries (Basile et al., 2011; Williams, 2012). Two factors contributed to these differences between the two zones. First, a greater water deficit advanced the berry maturation, leading to a higher TSS and lower TA (Escalona et al., 2015). Second, berry dehydration may have occurred and the TSS concentration increased in the berries. In our study, smaller berries were observed in Zone 1, which can confirm the berry dehydration could have led to higher TSS in Zone 1. As for berry TA, one study showed that grape organic acids biodegradation would be faster with more solar radiation and higher temperature (Cholet et al., 2016). Although the acid degradation was not related to water deficits, like mentioned above, water deficits would limit the grapevines' ability to regulate temperature (Tombesi et al., 2015). Thus, water 
deficits could promote the organic acid degradation and this effect was observed in this study.

\section{Berry Skin and Wine Flavonoids}

Mild water deficits increased the flavonoid content and concentration of red-skinned grape berry due to the upregulation in flavonoid synthesis and the advancement of berry dehydration during growing season (Castellarin et al., 2007a; Bondada and Shutthanandan, 2012). A positive relationship was noticed between soil bulk EC and total skin anthocyanins in 2017 at both depths of soil bulk EC measurements. A more prolonged severe water deficit would lead to deleterious stomatal and temperature regulation and eventually resulted in flavonoid degradation, specifically anthocyanins (Movahed et al., 2016). This was a plausible explanation for the non-significant relationship between soil bulk EC and total skin anthocyanins in 2016, wherein harvest took place at higher soluble solids and Zone 1 berry skin anthocyanins were presumably in decline. Furthermore, the berry weights were higher in Zone 2, which was similar to the observations in our previous work (MartínezLüscher et al., 2017), indicating there was less berry dehydration. Thus, the higher anthocyanins in Zone 2 was mainly due to the upregulation in anthocyanins other than anthocyanins degradation. These effects were also observed in the wines of 2016, where Zone 2 had higher anthocyanin concentrations. However, in the second season, the differences in berry skin anthocyanins at harvest did not carry over into the wines. We contributed this to the more advanced berry maturity levels at harvest in the first season, the skin cell walls could have become more porous during ripening and increased the extractability of flavonoid compounds (Bindon et al., 2014). With relatively greater amounts of flavonoids extracted, there was a higher chance to pass on the separations of anthocyanins from the berries to the wines.

Grape berry skin proanthocyanidins are less sensitive toward water deficits than anthocyanins (Castellarin et al., 2007a; Cáceres-Mella et al., 2017). Nevertheless, their biosynthesis and concentration may be modified by water deficits (Ollé et al., 2011; Cáceres-Mella et al., 2017). In 2016, wine total proanthocyanidins and all the subunits were greater in Zone 2. These differences were not observed in the second season. We attributed this lack of consistency in proanthocyanidin disparities between the two zones to the more advanced maturity of the berries were harvested in 2016 than in 2017. We suggest that similar to skin anthocyanins, the more advanced berry maturity in 2016 could

\section{REFERENCES}

Basile, B., Marsal, J., Mata, M., Vallverdú, X., Bellvert, J., and Girona, J. (2011). Phenological sensitivity of Cabernet Sauvignon to water stress: vine physiology and berry composition. Am. J. Enol. Viticult. 62, 452-461. doi: 10.5344/ajev. 2011.11003

Bindon, K. A., Madani, S. H., Pendleton, P., Smith, P. A., and Kennedy, J. A. (2014). Factors affecting skin tannin extractability in ripening grapes. J. Agric. Food Chem. 62, 1130-1141. doi: 10.1021/jf4050606

Bittelli, M. (2011). Measuring soil water content: a review. HortTechnology 21, 293-300. doi: 10.21273/horttech.21.3.293 have promoted the proanthocyanidin extractability in the skin tissues (Bindon et al., 2014), which may augment the separations in the concentration of all the subunits between the two zones.

\section{CONCLUSION}

Our work provided evidence of the connection between soil bulk EC sensing and whole plant physiology, and the effects of which then cascaded to berry and wine chemistry. We presented that soil bulk EC in vineyard systems affected plant water status. The clusters of plants with similar water status may comprise zones of similar physiological behavior due to these inherent differences from different plant water status, and the discrepancies in plant water status resulted in cascading effects on berry chemistry. In conclusion, our work provides fundamental knowledge about the applicability of soil bulk EC sensing in the vineyards, and its potential directional utilization by connecting proximal sensing to spatial distribution of whole-plant physiological performance together with berry and wine chemistry.

\section{DATA AVAILABILITY STATEMENT}

The raw data supporting the conclusions of this article will be made available by the authors, without undue reservation, to any qualified researcher.

\section{AUTHOR CONTRIBUTIONS}

SK acquired the funding and designed the trial. LB, RY, and JM-L executed the trial. RY made the wine, analyzed the metabolites, and wrote the first version of the manuscript. All authors contributed to the final version and approved.

\section{FUNDING}

The authors acknowledge the USDA-NIFA Specialty Crop Research Initiative award no. 2015-51181-24393 for funding during the execution of the study. A graduate stipend was provided to RY by the Department of Viticulture and Enology at UC Davis, Horticulture and Agronomy Graduate Group at UC Davis, and American Society for Enology and Viticulture.

Bondada, B., and Shutthanandan, J. (2012). Understanding differential responses of grapevine (Vitis vinifera L.) leaf and fruit to water stress and recovery following re-watering. Am. J. Plant Sci. 3:1232. doi: 10.4236/ajps.2012.39149

Bonfante, A., Agrillo, A., Albrizio, R., Basile, A., Buonomo, R., De Mascellis, R., et al. (2015). Functional homogeneous zones (fHZs) in viticultural zoning procedure: an Italian case study on Aglianico vine. Soil 1, 427-441. doi: 10. 5194/soil-1-427-2015

Bramley, R., Ouzman, J., and Boss, P. (2011a). Variation in vine vigour, grape yield and vineyard soils and topography as indicators of variation in the chemical composition of grapes, wine and wine sensory attributes. Aust. J. Grape Wine Res. 17, 217-229. doi: 10.1111/j.1755-0238.2011.00136.x 
Bramley, R., Ouzman, J., and Thornton, C. (2011b). Selective harvesting is a feasible and profitable strategy even when grape and wine production is geared towards large fermentation volumes. Aust. J. Grape Wine Res. 17, 298-305. doi: 10.1111/j.1755-0238.2011.00151.x

Bramley, R., Trought, M. C., and Praat, J. P. (2011c). Vineyard variability in Marlborough, New Zealand: characterising variation in vineyard performance and options for the implementation of Precision Viticulture. Aust. J. Grape Wine Res. 17, 72-78. doi: 10.1111/j.1755-0238.2010.00119.x

Brillante, L., Bois, B., Lévêque, J., and Mathieu, O. (2016a). Variations in soil-water use by grapevine according to plant water status and soil physical-chemical characteristics-A 3D spatio-temporal analysis. Eur. J. Agron. 77, 122-135. doi: 10.1016/j.eja.2016.04.004

Brillante, L., Bois, B., Mathieu, O., and Lévêque, J. (2016b). Electrical imaging of soil water availability to grapevine: a benchmark experiment of several machinelearning techniques. Precision Agricult. 17, 637-658. doi: 10.1007/s11119-0169441- 1

Brillante, L., Bois, B., Mathieu, O., Bichet, V., Michot, D., and Lévêque, J. (2014). Monitoring soil volume wetness in heterogeneous soils by electrical resistivity. A field-based pedotransfer function. J. Hydrol. 516, 56-66. doi: 10.1016/j. jhydrol.2014.01.052

Brillante, L., Martinez-Luscher, J., Yu, R., Plank, C. M., Sanchez, L., Bates, T. L., et al. (2017). Assessing spatial variability of grape skin flavonoids at the vineyard scale based on plant water status mapping. J. Agric. Food Chem. 65, 5255-5265. doi: 10.1021/acs.jafc.7b01749

Brillante, L., Mathieu, O., Bois, B., Van Leeuwen, C., and Lévêque, J. (2015). The use of soil electrical resistivity to monitor plant and soil water relationships in vineyards. Soil 1, 273-286. doi: 10.5194/soil-1-273-2015

Bucchetti, B., Matthews, M. A., Falginella, L., Peterlunger, E., and Castellarin, S. D. (2011). Effect of water deficit on Merlot grape tannins and anthocyanins across four seasons. Sci. Horticult. 128, 297-305. doi: 10.1016/j.scienta.2011. 02.003

Cáceres-Mella, A., Talaverano, M. I., Villalobos-González, L., Ribalta-Pizarro, C., and Pastenes, C. (2017). Controlled water deficit during ripening affects proanthocyanidin synthesis, concentration and composition in Cabernet Sauvignon grape skins. Plant Physiol. Biochem. 117, 34-41. doi: 10.1016/j. plaphy.2017.05.015

Castellarin, S. D., Matthews, M. A., Di Gaspero, G., and Gambetta, G. A. (2007a). Water deficits accelerate ripening and induce changes in gene expression regulating flavonoid biosynthesis in grape berries. Planta 227, 101-112. doi: 10.1007/s00425-007-0598-8

Castellarin, S. D., Pfeiffer, A., Sivilotti, P., Degan, M., Peterlunger, E., and Di Gaspero, G. (2007b). Transcriptional regulation of anthocyanin biosynthesis in ripening fruits of grapevine under seasonal water deficit. Plant Cell Environ. 30, 1381-1399. doi: 10.1111/j.1365-3040.2007.01716.x

Charrad, M., Ghazzali, N., Boiteau, V., and Niknafs, A. (2014). NbClust: an R Package for determining the relevant number of clusters in a data set. J. Stat. Softw. 61:36.

Cholet, C., Claverol, S., Claisse, O., Rabot, A., Osowsky, A., Dumot, V., et al. (2016). Tartaric acid pathways in Vitis vinifera L.(cv. Ugni blanc): a comparative study of two vintages with contrasted climatic conditions. BMC Plant Biol. 16:144. doi: 10.1186/s12870-016-0833-1

Cortell, J. M., Halbleib, M., Gallagher, A. V., Righetti, T. L., and Kennedy, J. A. (2007). Influence of vine vigor on grape (Vitis vinifera L. cv. Pinot Noir) anthocyanins. 1. Anthocyanin concentration and composition in fruit. J. Agricult. Food Chem. 55, 6575-6584. doi: 10.1021/jf070 $195 \mathrm{v}$

Costa, J. M., Ortuño, M. F., Lopes, C. M., and Chaves, M. M. (2012). Grapevine varieties exhibiting differences in stomatal response to water deficit. Funct. Plant Biol. 39, 179-189.

Dai, Z. W., Meddar, M., Renaud, C., Merlin, I., Hilbert, G., Delrot, S., et al. (2014). Long-term in vitro culture of grape berries and its application to assess the effects of sugar supply on anthocyanin accumulation. J. Exp. Bot. 65, 4665-4677. doi: $10.1093 /$ jxb/ert489

Escalona, J., Bota, J., and Medrano, H. (2015). Distribution of leaf photosynthesis and transpiration within grapevine canopies under different drought conditions. VITIS J. Grapevine Res. 42:57.

Gonzalo-Diago, A., Dizy, M., and Fernaindez-Zurbano, P. N. (2013). Taste and mouthfeel properties of red wines proanthocyanidins and their relation to the chemical composition. J. Agricult. Food Chem. 61, 8861-8870. doi: 10.1021/ jf401041q

Hiemstra, P. (2013). Package 'automap'. R Package.

Hijmans, R. J., Van Etten, J., Cheng, J., Mattiuzzi, M., Sumner, M., Greenberg, J. A., et al. (2015). Package 'raster'. R package.

Intrigliolo, D., Pérez, D., Risco, D., Yeves, A., and Castel, J. (2012). Yield components and grape composition responses to seasonal water deficits in Tempranillo grapevines. Irrigat. Sci. 30, 339-349. doi: 10.1007/s00271-0120354-0

Intrigliolo, D. S., and Castel, J. R. (2010). Response of grapevine cv.'Tempranillo’to timing and amount of irrigation: water relations, vine growth, yield and berry and wine composition. Irrigati. Sci. 28:113. doi: 10.1007/s00271-009-0164-1

Kennedy, J. A., and Jones, G. P. (2001). Analysis of proanthocyanidin cleavage products following acid-catalysis in the presence of excess phloroglucinol. J. Agric. Food Chem. 49, 1740-1746. doi: 10.1021/jf001030o

Korkutal, I., Bahar, E., and Carbonneau, A. (2011). Growth and yield responses of cv. Merlot (Vitis vinifera L.) to early water stress. Afr. J. Agricult. Res. 6, 6281-6288.

Lorrain, B., Ky, I., Pechamat, L., and Teissedre, P.-L. (2013). Evolution of analysis of polyhenols from grapes, wines, and extracts. Molecules 18, 1076-1100. doi: 10.3390/molecules 18011076

Martínez-Lüscher, J., Brillante, L., and Kurtural, S. K. (2019). Flavonol profile is a reliable indicator to assess canopy architecture and the exposure of red wine grapes to solar radiation. Front. Plant Sci. 10:10. doi: 10.3389/fpls.2019.00010

Martínez-Lüscher, J., Brillante, L., Nelson, C. C., Al-Kereamy, A. M., Zhuang, S. and Kurtural, S. K. (2017). Precipitation before bud break and irrigation affect the response of grapevine 'Zinfandel'yields and berry skin phenolic composition to training systems. Sci. Horticult. 222, 153-161. doi: 10.1016/j.scienta.2017. 05.011

Martínez-Lüscher, J., Sánchez-Díaz, M., Delrot, S., Aguirreolea, J., Pascual, I., and Gomès, E. (2014). Ultraviolet-B radiation and water deficit interact to alter flavonol and anthocyanin profiles in grapevine berries through transcriptomic regulation. Plant Cell Physiol. 55, 1925-1936. doi: 10.1093/pcp/pcu121

Matese, A., Toscano, P., Di Gennaro, S., Genesio, L., Vaccari, F., Primicerio, J., et al. (2015). Intercomparison of UAV, aircraft and satellite remote sensing platforms for precision viticulture. Remote Sens. 7, 2971-2990. doi: 10.3390/rs70302971

Morari, F., Castrignanò, A., and Pagliarin, C. (2009). Application of multivariate geostatistics in delineating management zones within a gravelly vineyard using geo-electrical sensors. Comput. Electr. Agricult. 68, 97-107. doi: 10.1016/j. compag.2009.05.003

Movahed, N., Pastore, C., Cellini, A., Allegro, G., Valentini, G., Zenoni, S., et al (2016). The grapevine VviPrx31 peroxidase as a candidate gene involved in anthocyanin degradation in ripening berries under high temperature. J. Plant Res. 129, 513-526. doi: 10.1007/s10265-016-0786-3

Ollé, D., Guiraud, J.-L., Souquet, J. M., Terrier, N., Ageorges, A., Cheynier, V. et al. (2011). Effect of pre-and post-veraison water deficit on proanthocyanidin and anthocyanin accumulation during Shiraz berry development. Aust. J. Grape Wine Res. 17, 90-100. doi: 10.1111/j.1755-0238.2010.00121.x

Pebesma, E. J. (2004). Multivariable geostatistics in S: the gstat package. Comput. Geosci. 30, 683-691. doi: 10.1016/j.cageo.2004.03.012

Petrussa, E., Braidot, E., Zancani, M., Peresson, C., Bertolini, A., Patui, S., et al. (2013). Plant flavonoids-biosynthesis, transport and involvement in stress responses. Int. J. Mol. Sci. 14, 14950-14973. doi: 10.3390/ijms140714950

R Core Team, (2019). R: A Language and Environment for Statistical Computing. Vienna: R Core Team.

Rodríguez-Pérez, J. R., Plant, R. E., Lambert, J.-J., and Smart, D. R. (2011). Using apparent soil electrical conductivity (EC a) to characterize vineyard soils of high clay content. Precis. Agricult. 12, 775-794. doi: 10.1007/s11119-011-9220-y

Santesteban, L., Miranda, C., and Royo, J. (2011). Regulated deficit irrigation effects on growth, yield, grape quality and individual anthocyanin composition in Vitis vinifera L. cv.'Tempranillo’. Agricult. Water Manag. 98, 1171-1179. doi: 10.1016/j.agwat.2011.02.011

Scarlett, N., Bramley, R., and Siebert, T. (2014). Within-vineyard variation in the 'pepper'compound rotundone is spatially structured and related to variation in the land underlying the vineyard. Aust. J. Grape Wine Res. 20, 214-222. doi: 10.1111/ajgw.12075

Smart, R. E., and Coombe, B. G. (1983). Water Relations of Grapevines [Vitis]. Water Deficits and Plant Growth. Paris: FAO. 
Spayd, S. E., Tarara, J. M., Mee, D. L., and Ferguson, J. (2002). Separation of sunlight and temperature effects on the composition of Vitis vinifera $\mathrm{cv}$. Merlot berries. Am. J. Enol. Viticult. 53, 171-182.

Su, S. L., Singh, D., and Baghini, M. S. (2014). A critical review of soil moisture measurement. Measurement 54, 92-105. doi: 10.1016/j.measurement.2014.04. 007

Tagarakis, A., Liakos, V., Fountas, S., Koundouras, S., and Gemtos, T. (2013). Management zones delineation using fuzzy clustering techniques in grapevines. Precis. Agricult. 14, 18-39. doi: 10.1007/s11119-0129275-4

Tarara, J. M., Peña, J. E. P., Keller, M., Schreiner, R. P., and Smithyman, R. P. (2011). Net carbon exchange in grapevine canopies responds rapidly to timing and extent of regulated deficit irrigation. Funct. Plant Biol. 38, 386-400.

Terry, D. B., and Kurtural, S. K. (2011). Achieving vine balance of Syrah with mechanical canopy management and regulated deficit irrigation. Am. J. Enol. Viticult. 62, 426-437. doi: 10.5344/ajev.2011.11022

Tombesi, S., Nardini, A., Frioni, T., Soccolini, M., Zadra, C., Farinelli, D., et al. (2015). Stomatal closure is induced by hydraulic signals and maintained by ABA in drought-stressed grapevine. Sci. Rep. 5:12449.

Tramontini, S., Van Leeuwen, C., Domec, J.-C., Destrac-Irvine, A., Basteau, C., Vitali, M., et al. (2013). Impact of soil texture and water availability on the hydraulic control of plant and grape-berry development. Plant Soil 368, 215230. doi: $10.1007 / \mathrm{s} 11104-012-1507-\mathrm{x}$
Williams, L. E. (2010). Interaction of rootstock and applied water amounts at various fractions of estimated evapotranspiration (ETc) on productivity of Cabernet Sauvignon. Aust. J. Grape Wine Res. 16, 434-444. doi: 10.1111/j.17550238.2010.00104.x

Williams, L. E. (2012). Interaction of applied water amounts and leaf removal in the fruiting zone on grapevine water relations and productivity of Merlot. Irrigat. Sci. 30, 363-375. doi: 10.1007/s00271-012-0355-Z

Yu, R., and Kurtural, S. K. (2020). Proximal sensing of soil electrical conductivity provides a link to soil-plant water relationships and supports the identification of plant water status zones in vineyards. Front. Plant Sci. 11:244. doi: 10.3389/ fpls.2020.00244

Conflict of Interest: The authors declare that the research was conducted in the absence of any commercial or financial relationships that could be construed as a potential conflict of interest.

Copyright (C) $2020 \mathrm{Yu}$, Brillante, Martinez-Lüscher and Kurtural. This is an openaccess article distributed under the terms of the Creative Commons Attribution License (CC BY). The use, distribution or reproduction in other forums is permitted, provided the original author(s) and the copyright owner(s) are credited and that the original publication in this journal is cited, in accordance with accepted academic practice. No use, distribution or reproduction is permitted which does not comply with these terms. 